Supporting Information

\title{
Microwave-mediated Nickel-catalyzed Cyclotrimerization Reactions: Total Synthesis of Illudinine
}

\author{
Jesse A. Teske and Alexander Deiters* \\ North Carolina State University, Department of Chemistry, Raleigh, NC 27695, USA, \\ alex_deiters@ncsu.edu
}

Table of Contents

Experimental data for compounds 9-15, 18-27

Experimental protocols of the illudinine synthesis

and experimental data for compounds 29, 31-36

Microwave pressure/temperature curves for representative cyclotrimerizations

${ }^{1} \mathrm{H}$ NMR spectra for compounds $9-15,18-27,29$, and $31-36$

${ }^{13} \mathrm{C}$ NMR spectrum for compound $\mathbf{3 6}$
Page

S2

S5

S7

S10

S22 
Experimental data for compounds 9-15, 18-27, 29, and 31-36.

tert-Butyl-(2,2di(ethoxycarbonyl)-2,3-dihydro-1H-inden-6-yl)methylcarbamate (9): ${ }^{1} \mathrm{H}$ NMR $\left(300 \mathrm{MHz}, \mathrm{CDCl}_{3}\right) \delta$ 7.20-7.02 (m, $\left.3 \mathrm{H}\right), 4.78(\mathrm{br} \mathrm{s}, 1 \mathrm{H}), 4.30-4.16(\mathrm{~m}, 6 \mathrm{H})$, $3.56(\mathrm{~s}, 4 \mathrm{H}), 1.47(\mathrm{~s}, 9 \mathrm{H}), 1.26(\mathrm{t}, J=7.2 \mathrm{~Hz}, 6 \mathrm{H}) ;{ }^{13} \mathrm{C} \mathrm{NMR}\left(75 \mathrm{MHz}, \mathrm{CDCl}_{3}\right) \delta 171.7$, 156.0, 140.7, 139.3, 137.9, 126.5, 124.4, 123.5, 79.6, 61.8, 60.6, 44.7, 40.5, 40.3, 28.5, 14.1. HRMS calcd for $[\mathrm{M}+\mathrm{Na}]^{+} \mathrm{C}_{21} \mathrm{H}_{29} \mathrm{NO}_{6} \mathrm{Na} 414.1887$, found 414.1891.

5,6-Diethyl-indan-2,2-dicarboxylic acid diethyl ester (10): ${ }^{1} \mathrm{H}$ NMR (300 MHz, $\mathrm{CDCl}_{3}$ ) $\delta 7.01(\mathrm{~s}, 2 \mathrm{H}), 4.21$ (q, J = 7.2 Hz, $4 \mathrm{H}), 3.56(\mathrm{~s}, 4 \mathrm{H}), 2.62(\mathrm{q}, J=7.7 \mathrm{~Hz}, 4 \mathrm{H}), 1.27$ (t, $J=7.2 \mathrm{~Hz}, 6 \mathrm{H}), 1.21(\mathrm{t}, J=7.7 \mathrm{~Hz}, 6 \mathrm{H}) ;{ }^{13} \mathrm{C}$ NMR $\left(75 \mathrm{MHz}, \mathrm{CDCl}_{3}\right) \delta 172.0,140.6$, 137.7, 124.0, 61.7, 60.6, 40.4, 25.6, 15.5, 14.2. HRMS calcd for $[\mathrm{M}+\mathrm{H}]^{+} \mathrm{C}_{19} \mathrm{H}_{27} \mathrm{O}_{4}$ 319.1904 , found 319.1908 .

5-Butyl-1,3-dihydro-isoindole-2-carboxylic acid tert-butyl ester (11): ${ }^{1} \mathrm{H}$ NMR (300 $\left.\mathrm{MHz}, \mathrm{CDCl}_{3}\right) \delta$ 7.23-7.00 (m, 3 H), $4.67(\mathrm{~s}, 2 \mathrm{H}), 4.63(\mathrm{~s}, 2 \mathrm{H}), 2.63(\mathrm{t}, J=7.6 \mathrm{~Hz}, 2 \mathrm{H})$, 1.69-1.50 (m, $11 \mathrm{H}), 1.46-1.30(\mathrm{~m}, 2 \mathrm{H}), 0.95(\mathrm{t}, J=7.2 \mathrm{~Hz}, 3 \mathrm{H}) ;{ }^{3} \mathrm{C}$ NMR $(75 \mathrm{MHz}$, $\mathrm{CDCl}_{3}$, rotamers) $\delta 154.6,142.3,142.2,137.5,137.1,127.7,127.6,122.7,122.6$, $122.5,122.3,79.7,52.4,52.3,52.1,52.0,35.7,34.1,28.8,22.58,22.55,14.2$. HRMS calcd for $[\mathrm{M}+\mathrm{Na}]^{+} \mathrm{C}_{17} \mathrm{H}_{25} \mathrm{NO}_{2} \mathrm{Na} 298.1778$, found 298.1778.

5-Phenyl-1,3-dihydro-isoindole-2-carboxylic acid tert-butyl ester (12): ${ }^{1} \mathrm{H}$ NMR $\left(300 \mathrm{MHz}, \mathrm{CDCl}_{3}\right) \delta$ 7.64-7.26 (m, $\left.8 \mathrm{H}\right), 4.81-4.66(\mathrm{~m}, 4 \mathrm{H}), 1.57(\mathrm{~s}, 9 \mathrm{H}) ;{ }^{3} \mathrm{C}$ NMR $(75$ $\mathrm{MHz}, \mathrm{CDCl}_{3}$, rotamers) $\delta 155.6,141.0,140.9,138.1,137.7,136.5,136.1,128.9,127.4$, $127.2,126.6,126.5,123.1,122.9,121.6,121.3,79.9,52.5,52.3,52.2,52.0,28.8$. HRMS calcd for $[\mathrm{M}+\mathrm{H}]^{+} \mathrm{C}_{19} \mathrm{H}_{22} \mathrm{NO}_{2}$ 296.1645, found 296.1653.

5-(benzyloxymethyl)-1,3-dihydro-isoindole-2-carboxylic acid tert-butyl ester (13): ${ }^{1} \mathrm{H}$ NMR $\left(300 \mathrm{MHz}, \mathrm{CDCl}_{3}\right) \delta$ 7.42-7.18 (m, $\left.8 \mathrm{H}\right), 4.70(\mathrm{~s}, 2 \mathrm{H}), 4.67(\mathrm{~s}, 2 \mathrm{H}), 4.59$ (s, 2 $\mathrm{H}), 4.57(\mathrm{~s}, 2 \mathrm{H}), 1.55(\mathrm{~s}, 9 \mathrm{H}) ;{ }^{13} \mathrm{C}$ NMR $\left(75 \mathrm{MHz}, \mathrm{CDCl}_{3}\right.$, rotamers) $\delta$ 154.7, 138.3, $137.8,137.4,136.9,136.6,128.61,128.58,127.93,127.85,127.21,127.17,122.9$, 122.6, 122.4, 122.1, 79.9, 72.5, 72.4, 72.3, 72.1, 71.8, 52.4, 52.3, 52.1, 52.0, 51.6, 51.5, 28.9, 28.5. HRMS calcd for $[\mathrm{M}+\mathrm{Na}]^{+} \mathrm{C}_{21} \mathrm{H}_{26} \mathrm{NO}_{3} \mathrm{Na} 362.1727$, found 362.1742.

tert-Butyl (2-(tert-butoxycarbonyl)isoindolin-6-yl)methyl carbamate (14): ${ }^{1} \mathrm{H}$ NMR $\left(300 \mathrm{MHz}, \mathrm{CDCl}_{3}\right) \delta$ 7.26-7.10 (m, 3 H), $4.90(\mathrm{br} \mathrm{s}, 1 \mathrm{H}), 4.67(\mathrm{~s}, 2 \mathrm{H}), 4.64(\mathrm{~s}, 2 \mathrm{H})$, $4.33(\mathrm{~s}, 2 \mathrm{H}), 4.31(\mathrm{~s}, 2 \mathrm{H}), 1.54(\mathrm{~s}, 9 \mathrm{H}), 1.48(\mathrm{~s}, 9 \mathrm{H}) ;{ }^{13} \mathrm{C} \mathrm{NMR}\left(75 \mathrm{MHz}, \mathrm{CDCl}_{3}\right.$, rotamers) $\delta 155.6,154.5,138.5,137.9,137.5,136.5,136.1,126.7,122.9,122.7,121.8$, $121.7,79.8,79.7,52.4,52.2,52.1,51.9,44.7,28.8,28.6$. HRMS calcd for $[\mathrm{M}+\mathrm{Na}]^{+}$ $\mathrm{C}_{19} \mathrm{H}_{28} \mathrm{~N}_{2} \mathrm{O}_{4} \mathrm{Na} 371.1941$, found 371.1939.

5,6-Diethyl-1,3-dihydro-isoindole-2-carboxylic acid tert-butyl ester (15): ${ }^{1} \mathrm{H}$ NMR $\left(300 \mathrm{MHz}, \mathrm{CDCl}_{3}\right) \delta 7.09(\mathrm{~s}, 1 \mathrm{H}), 7.04(\mathrm{~s}, 1 \mathrm{H}), 4.66(\mathrm{~s}, 2 \mathrm{H}), 4.62(\mathrm{~s}, 2 \mathrm{H}), 2.68(\mathrm{q}, J=$ $7.4 \mathrm{~Hz}, 4 \mathrm{H}), 1.54(\mathrm{~s}, 9 \mathrm{H}), 1.25(\mathrm{t}, \mathrm{J}=7.4 \mathrm{~Hz}, 6 \mathrm{H}) ;{ }^{13} \mathrm{C} \mathrm{NMR}\left(75 \mathrm{MHz}, \mathrm{CDCl}_{3}\right.$, rotamers) $\delta 154.7,141.13,141.06,135.0,134.7,122.5,122.3,79.6,52.4,521,28.8$, 25.7, 15.7. HRMS calcd for $[\mathrm{M}+\mathrm{Na}]^{+} \mathrm{C}_{17} \mathrm{H}_{25} \mathrm{NO}_{2} \mathrm{Na} 298.1778$, found 298.1778. 
Diethyl-5-butyl-4,7-indanedicarboxylate (18): NMR (300 MHz, CDCl 3$) \delta 7.70(\mathrm{~s}, 1 \mathrm{H})$, 4.48-4.28 (m, $4 \mathrm{H}), 3.25(\mathrm{t}, J=7.4 \mathrm{~Hz}, 2 \mathrm{H}), 2.97(\mathrm{t}, J=7.4 \mathrm{~Hz}, 2 \mathrm{H}), 2.72(\mathrm{t}, J=7.7 \mathrm{~Hz}$, $2 \mathrm{H}), 2.08(\mathrm{p}, J=7.4 \mathrm{~Hz}, 2 \mathrm{H}), 1.58(\mathrm{p}, J=7.7 \mathrm{~Hz}, 2 \mathrm{H}), 1.46-1.30(\mathrm{~m}, 8 \mathrm{H}), 0.93(\mathrm{t}, J=$ $7.4 \mathrm{~Hz}, 3 \mathrm{H}) ;{ }^{13} \mathrm{C}$ NMR $\left(75 \mathrm{MHz}, \mathrm{CDCl}_{3}\right) \delta 168.8,166.8,144.6,144.5,139.0,132.9$, $129.7,127.9,61.2,61.0,34.2,33.9,33.4,32.4,25.1,22.9,14.6,14.5,14.2$. HRMS calcd for $[\mathrm{M}+\mathrm{H}]^{+} \mathrm{C}_{19} \mathrm{H}_{27} \mathrm{O}_{4} 319.1909$, found 319.1919.

Diethyl-5-Phenyl-4,7-indanedicarboxylate (19): NMR (300 MHz, $\left.\mathrm{CDCl}_{3}\right) \delta 7.88$ (s, 1 H), 7.46-7.30 (m, $5 \mathrm{H}), 4.39(\mathrm{q}, J=7.2 \mathrm{~Hz}, 2 \mathrm{H}), 4.11(\mathrm{q}, J=6.9 \mathrm{~Hz}, 2 \mathrm{H}), 3.36(\mathrm{t}, J=$ $7.6 \mathrm{~Hz}, 2 \mathrm{H}$ ), 3.08 (t, $J=7.6 \mathrm{~Hz}, 2 \mathrm{H}), 2.17$ (p, $J=7.6 \mathrm{~Hz}, 2 \mathrm{H}), 1.42(\mathrm{t}, J=7.2 \mathrm{~Hz}, 3 \mathrm{H}$ ), $1.009 \mathrm{t}, J=6.9 \mathrm{~Hz}, 3 \mathrm{H}) ;{ }^{13} \mathrm{C} \mathrm{NMR}\left(75 \mathrm{MHz}, \mathrm{CDCl}_{3}\right) \delta 168.8,166.5,146.4,145.0,140.5$, $138.9,132.5,129.9,128.4,128.3,127.9,127.4,61.2,61.1,34.0,32.1,25.1,14.6,13.9$. HRMS calcd for $[\mathrm{M}+\mathrm{H}]^{+} \mathrm{C}_{21} \mathrm{H}_{23} \mathrm{O}_{4} 339.1596$, found 339.1589.

Diethyl-5-(benzyloxymethyl)-4,7-indanedicarboxylate (20): NMR (300 MHz, $\left.\mathrm{CDCl}_{3}\right) \delta$ $7.92(\mathrm{~s}, 1 \mathrm{H}), 7.41-7.26(\mathrm{~m}, 5 \mathrm{H}), 4.74(\mathrm{~s}, 2 \mathrm{H}), 4.54(\mathrm{~s}, 2 \mathrm{H}), 4.45-4.29(\mathrm{~m}, 4 \mathrm{H}), 3.30(\mathrm{t}$, $J=7.6 \mathrm{~Hz}, 2 \mathrm{H}), 3.05(\mathrm{t}, J=7.6 \mathrm{~Hz}, 2 \mathrm{H}), 2.12(\mathrm{p}, J=7.6 \mathrm{~Hz}, 2 \mathrm{H}), 1.43(\mathrm{t}, J=7.2 \mathrm{~Hz}, 3$ $\mathrm{H}), 1.35(\mathrm{t}, J=7.2 \mathrm{~Hz}, 3 \mathrm{H}) ;{ }^{13} \mathrm{C}$ NMR $\left(75 \mathrm{MHz}, \mathrm{CDCl}_{3}\right) \delta 168.2,166.5,147.2,145.5$, $138.1,135.2,132.0,128.6,128.4,127.9,127.8,127.6,72.6,70.3,61.3,61.1,33.9$, 32.4, 25.1, 14.6, 14.4. HRMS calcd for $\left[\mathrm{M}+\mathrm{H}^{+} \mathrm{C}_{23} \mathrm{H}_{27} \mathrm{O}_{5}\right.$ 383.1858, found 383.1854.

tert-Butyl-(4,7-di(ethoxycarbonyl)-2,3-1 H-inden-5-yl)methylcarbamate (21): NMR $\left(300 \mathrm{MHz}, \mathrm{CDCl}_{3}\right) \delta 7.88(\mathrm{~s}, 1 \mathrm{H}), 5.22(\mathrm{br} \mathrm{s}, 1 \mathrm{H}), 4.51-4.32(\mathrm{~m}, 4 \mathrm{H}), 3.29(\mathrm{t}, J=7.6$ $\mathrm{Hz}, 2 \mathrm{H}), 3.06(\mathrm{t}, J=7.6 \mathrm{~Hz}, 2 \mathrm{H}), 2.10(\mathrm{p}, J=7.6 \mathrm{~Hz}, 2 \mathrm{~h}), 1.54-1.37(\mathrm{~m}, 15 \mathrm{H}) ;{ }^{13} \mathrm{C}$ NMR $\left(75 \mathrm{MHz}, \mathrm{CDCl}_{3}\right) \delta 168.3,166.3,155.6,147.1,146.1,136.2,131.6,129.6,128.7$, $79.4,61.6,61.1,43.3,33.8,33.0,28.6,25.1,14.6,14.5$. HRMS calcd for $[\mathrm{M}+\mathrm{H}]^{+}$ $\mathrm{C}_{21} \mathrm{H}_{30} \mathrm{NO}_{6}$ 392.2073, found 392.2069.

Diethyl-5,6-diethyl-4,7-indanedicarboxylate (22): NMR (300 MHz, $\left.\mathrm{CDCl}_{3}\right) \delta 4.40$ (q, J $=7.2 \mathrm{~Hz}, 4 \mathrm{H}$ ), $2.93(\mathrm{t}, J=7.4 \mathrm{~Hz}, 4 \mathrm{H}), 2.73(\mathrm{q}, J=7.5 \mathrm{~Hz}, 4 \mathrm{H}), 2.07(\mathrm{p}, J=7.4 \mathrm{~Hz}, 2$ $\mathrm{H}), 1.41(\mathrm{t}, J=7.2 \mathrm{~Hz}, 6 \mathrm{H}), 1.21(\mathrm{t}, J=7.5 \mathrm{~Hz}, 6 \mathrm{H}) ;{ }^{13} \mathrm{C} \mathrm{NMR}\left(75 \mathrm{MHz}, \mathrm{CDCl}_{3}\right) \delta$ $169.5,140.5,138.0,131.9,61.1,32.3,25.0,23.4,16.3,14.5$. HRMS calcd for $[\mathrm{M}+\mathrm{H}]^{+}$ $\mathrm{C}_{19} \mathrm{H}_{27} \mathrm{O}_{4} 319.1909$, found 319.1910.

3-Butyl-5,7,6,8-naphthalene-1,4-dicarboxylic acid diethyl ester (23): NMR (300 $\left.\mathrm{MHz}, \mathrm{CDCl}_{3}\right) \delta 7.49(\mathrm{~s}, 1 \mathrm{H}), 4.38(\mathrm{~m}, 4 \mathrm{H}), 3.02(\mathrm{br} \mathrm{s}, 2 \mathrm{H}), 2.74(\mathrm{br} \mathrm{s}, 2 \mathrm{H}), 2.55(\mathrm{t}, J=$ $8.0 \mathrm{~Hz}, 2 \mathrm{H}), 1.85-1.73(\mathrm{~m}, 4 \mathrm{H}), 1.67-1.53(\mathrm{~m}, 2 \mathrm{H}), 1.47-1.30(\mathrm{~m}, 8 \mathrm{H}), 0.94(\mathrm{t}, J=7.2$ $\mathrm{Hz}, 3 \mathrm{H}) ;{ }^{13} \mathrm{C}$ NMR $\left(75 \mathrm{MHz}, \mathrm{CDCl}_{3}\right) \delta 169.7,168.0,137.3,136.0,135.9,134.4,131.7$, 128.3, 61.3, 61.1, 33.6, 33.2, 27.9, 27.5, 22.9, 22.8, 22.4, 14.6, 14.5, 14.1. HRMS calcd for $[\mathrm{M}+\mathrm{H}]^{+} \mathrm{C}_{20} \mathrm{H}_{29} \mathrm{O}_{4} 333.2066$, found 333.2073.

3-Phenyl-5,7,6,8-naphthalene-1,4-dicarboxylic acid diethyl ester (24): NMR (300 $\left.\mathrm{MHz} \mathrm{CDCl}_{3}\right) \delta 7.66(\mathrm{~s}, 1 \mathrm{H}), 7.44-7.32(\mathrm{~m}, 5 \mathrm{H}), 4.36(\mathrm{q}, J=7.2 \mathrm{~Hz}, 2 \mathrm{H}), 4.08(\mathrm{q}, J=$ $7.2 \mathrm{~Hz}, 2 \mathrm{H}), 3.12$ (br s, $2 \mathrm{H}), 2.85$ (br s, $2 \mathrm{H}), 1.92-1.77$ (m, $4 \mathrm{H}), 1.39$ (t, J = 7.2 Hz, 3 $\mathrm{H}), 1.01(\mathrm{t}, J=7.2 \mathrm{~Hz}, 3 \mathrm{H}) ;{ }^{13} \mathrm{C}$ NMR $\left(75 \mathrm{MHz}, \mathrm{CDCl}_{3}\right) \delta 169.2,167.6,140.0,137.7$, 
136.8, 136.6, 135.2, 131.8, 128.7, 128.5, 128.3, 127.6, 61.23, 61.17, 28.1, 27.7, 22.7, 22.4, 14.6, 14.0. HRMS calcd for $\left[\mathrm{M}+\mathrm{H}^{+} \mathrm{C}_{22} \mathrm{H}_{25} \mathrm{O}_{4} 353.1747\right.$, found 353.1753.

3-(Benzyloxymethyl)-5,7,6,8-naphthalene-1,4-dicarboxylic acid diethyl ester (25): $\operatorname{NMR}\left(300 \mathrm{MHz}, \mathrm{CDCl}_{3}\right) \delta 7.68(\mathrm{~s}, 1 \mathrm{H}), 7.41-7.28(\mathrm{~m}, 5 \mathrm{H}), 4.58(\mathrm{~s}, 2 \mathrm{H}), 4.51(\mathrm{~s}, 2 \mathrm{H})$, 4.43-4.24 (m, $4 \mathrm{H}), 3.08$ (br s, $2 \mathrm{H}), 2.80$ (br s, $2 \mathrm{H}), 1.89-1.75(\mathrm{~m}, 4 \mathrm{H}), 1.41$ (t, $J=7.2$ $\mathrm{Hz}, 3 \mathrm{H}), 1.32(\mathrm{t}, J=7.2 \mathrm{~Hz}, 3 \mathrm{H}) ;{ }^{13} \mathrm{C}$ NMR $\left(75 \mathrm{MHz}, \mathrm{CDCl}_{3}\right) \delta 169.1,167.6,138.5$, 138.0, 136.5, 135.4, 132.2, 131.7, 128.4, 127.8, 127.7,127.6, 72.5, 70.0, 61.4, 61.1, $28.1,27.6,22.7,22.3,14.6,14.3$. HRMS calcd for $\left[\mathrm{M}+\mathrm{Na}^{+} \mathrm{C}_{24} \mathrm{H}_{28} \mathrm{O}_{5} \mathrm{Na} 419.1828\right.$, found 419.1836 .

tert-Butyl-(5,8-di(ethoxycarbonyl)-1,2,3,4-tetrahydronaphthalen-7yl)methylcarbamate (26): NMR (300 MHz, $\left.\mathrm{CDCl}_{3}\right) \delta 7.64$ 9s, $\left.1 \mathrm{H}\right), 4.92(\mathrm{~s}, 1 \mathrm{H}), 4.48$ $4.30(\mathrm{~m}, 4 \mathrm{H}), 4.27$ (s, $2 \mathrm{H}), 4.25$ (s, $2 \mathrm{H}), 3.05$ (br s, $2 \mathrm{H}), 2.77$ (br s, $2 \mathrm{H}), 1.86-1.75(\mathrm{~m}$, $4 \mathrm{H}), 1.52-1.36(\mathrm{~m}, 15 \mathrm{H}) ;{ }^{13} \mathrm{C}$ NMR $\left(75 \mathrm{MHz}, \mathrm{CDCl}_{3}\right) \delta 169.3,167.5,155.5,138.1$, 136.6, 135.4, 132.6, 132.2, 128.0, 61.7, 61.2, 42.8, 28.6, 28.0, 27.7, 22.6, 22.3, 14.54, 14.46. HRMS calcd for $[\mathrm{M}+\mathrm{Na}]^{+} \mathrm{C}_{22} \mathrm{H}_{31} \mathrm{NO}_{6} \mathrm{Na} 428.2043$, found 428.2051.

3,4-diethyl-5,7,6,8-naphthalene-1,4-dicarboxylic acid diethyl ester (27): NMR (300 $\left.\mathrm{MHz}, \mathrm{CDCl}_{3}\right) \delta 4.39(\mathrm{q}, J=7.2 \mathrm{~Hz}, 4 \mathrm{H}), 2.74-2.53(\mathrm{~m}, 8 \mathrm{H}), 1.85-1.71(\mathrm{~m}, 4 \mathrm{H}), 1.41(\mathrm{t}$, $J=7.2 \mathrm{~Hz}, 6 \mathrm{H}), 1.20(\mathrm{t}, J=7.6 \mathrm{~Hz}, 6 \mathrm{H}) ;{ }^{13} \mathrm{C} \mathrm{NMR}\left(75 \mathrm{MHz}, \mathrm{CDCl}_{3}\right) \delta 170.2,136.1$, 135.8, 131.4, 61.1, 26.9, 23.6, 22.7, 16.1, 14.5. HRMS calcd for $[\mathrm{M}+\mathrm{H}]^{+} \mathrm{C}_{20} \mathrm{H}_{29} \mathrm{O}_{4}$ 333.2066, found 333.2075. 


\section{Experimental protocols of the illudinine synthesis and experimental data for compounds 29, 31-36}

Diethyl-5,5-dimethylnona-2,7-diynedioate (29): $n$-BuLi (2.4 $\mathrm{M}$ in hexanes, $880 \mu \mathrm{L}$, $2.11 \mathrm{mmol})$ was added dropwise to a solution of $28(110 \mathrm{mg}, 0.92 \mathrm{mmol})$ in THF (11 $\mathrm{mL})$ at $-10^{\circ} \mathrm{C}$. The solution was stirred for 30 min before ethyl chloroformate $(228 \mu \mathrm{L}, 2.4$ $\mathrm{mmol}$ ) was added rapidly. The reaction was stirred at $-10^{\circ} \mathrm{C}$ for $10 \mathrm{~min}$, warmed to room temperature, and stirred for $1 \mathrm{~h}$. The reaction was quenched with sat. $\mathrm{NH}_{4} \mathrm{Cl}$ and extracted with $\mathrm{Et}_{2} \mathrm{O}$. The combined organic extracts were washed with $\mathrm{H}_{2} \mathrm{O}$ and brine, dried $\left(\mathrm{MgSO}_{4}\right)$, filtered and concentrated to dryness. The residue was purified by silica gel chromatography, eluting with hexanes/EtOAc $(10: 1)$ to give $167 \mathrm{mg}(70 \%)$ of 29 as a yellow oil. ${ }^{1} \mathrm{H}$ NMR $\left(300 \mathrm{MHz}, \mathrm{CDCl}_{3}\right) \delta 4.22$ (q, $\left.J=7.2 \mathrm{~Hz}, 2 \mathrm{H}\right), 2.38(\mathrm{~s}, 2 \mathrm{H}), 1.31$ (t, $J$ $=7.2 \mathrm{~Hz}, 3 \mathrm{H}), 1.14(\mathrm{~s}, 3 \mathrm{H}) ;{ }^{13} \mathrm{C}$ NMR $\left(75 \mathrm{MHz}, \mathrm{CDCl}_{3}\right) \delta 153.7,86.0,75.6,62.0,34.6$, 31.3, 26.7, 14.2. HRMS calcd for $\left[\mathrm{M}+\mathrm{H}^{+} \mathrm{C}_{15} \mathrm{H}_{21} \mathrm{O}_{4} 265.1434\right.$, found 265.1437.

1-[N-(tert-butoxycarbonyl)- $N$-(4-methoxybenzyl)amino]-2-[2,2-dimethyl-4,7di(ethoxycarbonyl)-indan-5-yl]ethane (31): In three microwave vials were added 29 (20 mg, $0.076 \mathrm{mmol}), 30$ (219 mg, $0.76 \mathrm{mmol}), \mathrm{Ni}(\mathrm{CO})_{2}\left(\mathrm{PPh}_{3}\right)_{2}(4.8 \mathrm{mg}, 0.0075 \mathrm{mmol})$, and $\mathrm{PhCH}_{3}(2.5 \mathrm{~mL})$. Each vial was irradiated for 2 min at $300 \mathrm{~W}$ in a CEM Discover microwave synthesizer. The reactions were combined and concentrated to dryness. The residue was purified by silica gel chromatography, eluting with hexanes/EtOAc (7:1) to give $105 \mathrm{mg}(84 \%)$ of $\mathbf{3 1}$ as an oil. ${ }^{1} \mathrm{H}$ NMR $\left(300 \mathrm{MHz}, \mathrm{CDCl}_{3}\right.$, rotamers) $\delta 7.75-7.59(\mathrm{~m}$, $1 \mathrm{H}), 7.25-7.09(\mathrm{~m}, 2 \mathrm{H}), 6.84(\mathrm{~d}, J=8.5 \mathrm{~Hz}, 2 \mathrm{H}), 4.42-4.18(\mathrm{~m}, 6 \mathrm{H}), 3.79(\mathrm{~s}, 3 \mathrm{H})$, 3.48-3.28 (m, $2 \mathrm{H}), 3.08$ (s, $2 \mathrm{H}), 3.03-2.84(\mathrm{~m}, 2 \mathrm{H}), 2.79$ (s, $2 \mathrm{H}), 1.48$ (s, $9 \mathrm{H}), 1.43-$ $1.33(\mathrm{~m}, 6 \mathrm{H}), 1.14(\mathrm{~s}, 6 \mathrm{H}) ;{ }^{13} \mathrm{C} \mathrm{NMR}\left(75 \mathrm{MHz}, \mathrm{CDCl}_{3}\right.$, rotamers) $\delta 168.4,166.6,158.9$, 155.9, 144.9, 144.4, 136.0, 133.2, 130.8, 130.5, 129.3, 128.7, 128.5, 113.9, 79.7, 61.3, $61.0,55.4,50.5,49.6,48.4,48.3,47.4,39.5$, 32.5, 32.2, 29.0, 28.6, 14.4. HRMS calcd for $[\mathrm{M}+\mathrm{Na}]^{+} \mathrm{C}_{32} \mathrm{H}_{43} \mathrm{NO}_{7} \mathrm{Na} 576.2932$, found 576.2932 .

1-[N-(tert-butoxycarbonyl)-N-(4-methoxybenzyl)amino]-2-[2,2-dimethyl-4(ethoxylcarbonyl)-7-(2-hydroxypropan-2-yl)-indane-5-yl]ethane (32): $\mathrm{CeCl}_{3}$ (69 mg, $0.28 \mathrm{mmol}$ ) was dried overnight in vacuo at $140^{\circ} \mathrm{C}$. While the flask was hot, nitrogen was introduced, and the flask was cooled to $0^{\circ} \mathrm{C}$. THF $(950 \mu \mathrm{L})$ was added at once, the ice bath removed, and the suspension stirred vigorously for 3 hrs at room temperature. The flask was cooled to $-78^{\circ} \mathrm{C}$, and $\mathrm{MeLi}\left(0.9 \mathrm{M}\right.$ in $\left.\mathrm{Et}_{2} \mathrm{O}, 313 \mu \mathrm{L}, 0.28 \mathrm{mmol}\right)$ was added dropwise. After stirring for $1 \mathrm{hr}$ at $-78^{\circ} \mathrm{C}, 31(26 \mathrm{mg}, 0.047 \mathrm{mmol})$ was added over $5 \mathrm{~min}$. After 9 min the reaction was quenched at $-78^{\circ} \mathrm{C}$ with sat. $\mathrm{NH}_{4} \mathrm{Cl}$ and allowed to warm to room temperature. EtOAc and water were added, and the layers were separated. The aqueous layer was extracted with EtOAc twice, and the combined organic extracts were washed with $\mathrm{H}_{2} \mathrm{O}$ and brine, dried $\left(\mathrm{Na}_{2} \mathrm{SO}_{4}\right)$, filtered, and concentrated to dryness. The residue was purified by silica gel chromatography, eluting with hexanes/EtOAc (2:7) to give $21.3 \mathrm{mg}(84 \%)$ of 32 as an oil. ${ }^{1} \mathrm{H}$ NMR $\left(300 \mathrm{MHz}, \mathrm{CDCl}_{3}\right.$, rotamers) $\delta$ 7.24-7.01 $(\mathrm{m}, 3 \mathrm{H}), 6.83(\mathrm{~d}, J=8.8 \mathrm{~Hz}, 2 \mathrm{H}), 4.40-4.17(\mathrm{~m}, 4 \mathrm{H}), 3.78(\mathrm{~s}, 3 \mathrm{H}), 3.37$ (br s, $2 \mathrm{H})$, 3.06-2.84 (m, $4 \mathrm{H}), 2.78(\mathrm{~s}, 2 \mathrm{H}), 1.81(\mathrm{~s}, 1 \mathrm{H}), 1.56(\mathrm{~s}, 6 \mathrm{H}), 1.45(\mathrm{~s}, 9 \mathrm{H}), 1.35(\mathrm{t}, J=$ $7.2 \mathrm{~Hz}, 3 \mathrm{H}), 1.13(\mathrm{~s}, 6 \mathrm{H}) ;{ }^{13} \mathrm{C}$ NMR $\left(75 \mathrm{MHz}, \mathrm{CDCl}_{3}\right.$, rotamers) $\delta 168.9,158.8,156.0$, $155.5,147.2$, 144.6, 139.0, 136.1, 130.75, 129.4, 128.7, 128.2, 125.5, 79.5, 73.1, 60.8, 
55.3, 50.3, 49.3, 48.7, 48.4, 48.0, 47.3, 39.6, 32.7, 30.4, 28.7, 28.6, 14.4. HRMS calcd for $[\mathrm{M}+\mathrm{Na}]^{+} \mathrm{C}_{32} \mathrm{H}_{45} \mathrm{NO}_{6} \mathrm{Na} 562.3139$, found 562.3141 .

\section{Ethyl-5-(2-(4-methoxybenzylamino)ethyl-7-hydroxy-2,2-dimethyl-4-carboxylate}

(33): $\mathrm{BF}_{3} \cdot \mathrm{Et}_{2} \mathrm{O}(83 \mu \mathrm{L}, 0.71 \mathrm{mmol})$ was added to $\mathrm{H}_{2} \mathrm{O}_{2}(50 \%, 5.4 \mu \mathrm{L}, 0.079 \mathrm{mmol})$ and stirred for $45 \mathrm{~min}$ at $0^{\circ} \mathrm{C}$. This solution was added to $32(21.3 \mathrm{mg}, 0.039 \mathrm{mmol})$ in dichloromethane $(950 \mu \mathrm{L})$ at $0^{\circ} \mathrm{C}$. After stirring for 9 min at $0^{\circ} \mathrm{C}, \mathrm{H}_{2} \mathrm{O}$ and EtOAc are added and the layers separated. The aqueous layer is extracted with EtOAc twice, and the combined organic extracts were washed with water and brine, dried $\left(\mathrm{Na}_{2} \mathrm{SO}_{4}\right)$, filtered and concentrated to dryness. The residue was purified by silica gel chromatography, eluting with $\mathrm{CHCl}_{3} / \mathrm{MeOH}(12: 1)$ to give $14.4 \mathrm{mg}(92 \%)$ of 33 as an oil. ${ }^{1} \mathrm{H}$ NMR $\left(300 \mathrm{MHz}, \mathrm{CDCl}_{3}\right) \delta 7.78(\mathrm{br} \mathrm{s}, 2 \mathrm{H}), 7.35(\mathrm{~d}, J=8.4 \mathrm{~Hz}, 2 \mathrm{H}), 6.78(\mathrm{~d}, J=8.4$ $\mathrm{Hz}, 2 \mathrm{H}), 6.71(\mathrm{~s}, 1 \mathrm{H}), 4.25(\mathrm{q}, J=7.2 \mathrm{~Hz}, 2 \mathrm{H}), 3.96(\mathrm{~s}, 2 \mathrm{H}), 3.68(\mathrm{~s}, 3 \mathrm{H}), 3.14(\mathrm{~m}, 4$ $\mathrm{H}), 2.85(\mathrm{~s}, 2 \mathrm{H}), 2.61(\mathrm{~s}, 2 \mathrm{H}), 1.31(\mathrm{t}, J=7.2 \mathrm{~Hz}, 3 \mathrm{H}), 1.10(\mathrm{~s}, 6 \mathrm{H}) ;{ }^{13} \mathrm{C}$ NMR $(75$ $\left.\mathrm{MHz}, \mathrm{CDCl}_{3}\right) \delta 168.9,160.2,156.3,148.1,138.0,131.6,129.6,123.6,119.4,116.6$, $114.4,61.0,55.3,51.3,49.8,48.5,43.5,39.5,31.5,29.2,14.4$. HRMS calcd for $[\mathrm{M}+\mathrm{H}]^{+}$ $\mathrm{C}_{24} \mathrm{H}_{32} \mathrm{NO}_{4}$ 398.2326, found 398.2334.

\section{Ethyl-2-(4-methoxybenzyl)-2,3,4,6,7,8-hexahydro-9-methoxy-7,7-dimethyl-1 $\mathrm{H}$ -} cyclopenta[g]isoquinoline-5-carboxylate (34): Formaldehyde (37\% in $\mathrm{H}_{2} \mathrm{O}, 29 \mu \mathrm{L}$, $0.39 \mathrm{mmol}$ ) was added to $33(14.4 \mathrm{mg}, 0.036 \mathrm{mmol})$ in $\mathrm{MeOH}(1.2 \mathrm{~mL}), 1 \mathrm{~N} \mathrm{NaOAc}$ $(510 \mu \mathrm{L})$, and $0.1 \mathrm{~N} \mathrm{HOAc}(510 \mu \mathrm{L})$, and the reaction was stirred at room temperature for $1 \mathrm{hr}$. The $\mathrm{MeOH}$ was removed and the aqueous layer extracted four times with dichloromethane. The combined organic extracts were dried $\left(\mathrm{Na}_{2} \mathrm{SO}_{4}\right)$, filtered and concentrated to dryness. The crude tetrahydroisoquinoline was then taken up in $\mathrm{CH}_{3} \mathrm{CN} / \mathrm{MeOH}(9: 2,160 \mu \mathrm{L})$, and DIPEA $(18.9 \mu \mathrm{L}, 0.11 \mathrm{mmol})$ followed by trimethylsilyldiazomethane ( $2 \mathrm{M}$ in $\left.\mathrm{Et}_{2} \mathrm{O}, 181 \mu \mathrm{L}, 0.36 \mathrm{mmol}\right)$. After $4 \mathrm{hrs}, 5$ equivalents more trimethylsilyldiazomethane $(90 \mu \mathrm{L})$ was added and the reaction was allowed to stir $30 \mathrm{~min}$. The solvent was then removed under reduced pressure, and the residue was taken up in $\mathrm{H}_{2} \mathrm{O}$ and EtOAc. The layers were separated, and the aqueous layer was extracted twice with EtOAc. The combined organic extracts were washed with water and brine, dried $\left(\mathrm{Na}_{2} \mathrm{SO}_{4}\right)$, filtered and concentrated. The residue was purified by silica gel chromatography, eluting with $\mathrm{CHCl}_{3} / \mathrm{MeOH}(45: 1)$ to give $10.1 \mathrm{mg}(66 \%, 2$ steps) of 34 as an oil. ${ }^{1} \mathrm{H}$ NMR $\left(300 \mathrm{MHz}, \mathrm{CDCl}_{3}\right) \delta 7.32(\mathrm{~d}, J=8.7 \mathrm{~Hz}, 2 \mathrm{H}), 6.88(\mathrm{~d}, J=8.7 \mathrm{~Hz}$, $2 \mathrm{H}), 4.32(\mathrm{q}, J=7.2 \mathrm{~Hz}, 2 \mathrm{H}), 3.82(\mathrm{~s}, 3 \mathrm{H}), 3.76(\mathrm{~s}, 3 \mathrm{H}), 3.65(\mathrm{~s}, 4 \mathrm{H}), 3.00(\mathrm{t}, J=5.9$ $\mathrm{Hz}, 2 \mathrm{H}), 2.82(\mathrm{~s}, 2 \mathrm{H}), 2.77(\mathrm{~s}, 2 \mathrm{H}), 2.64(\mathrm{t}, J=5.9 \mathrm{~Hz}, 2 \mathrm{H}), 1.35$ (t, J = 7.2 Hz, $3 \mathrm{H}$ ), $1.13(\mathrm{~s}, 6 \mathrm{H}) ;{ }^{13} \mathrm{C}$ NMR $\left(75 \mathrm{MHz}, \mathrm{CDCl}_{3}\right)^{1} \delta 166.6,158.9,155.3,144.8,134.3,131.2$, $130.4,126.2$, 123.9, 113.8, 62.0, 60.6, 59.5, 55.4, 51.9, 49.7, 48.2, 45.1, 40.1, 28.8, 28.2, 14.5. HRMS calcd for $[\mathrm{M}+\mathrm{H}]^{+} \mathrm{C}_{26} \mathrm{H}_{34} \mathrm{NO}_{4}$ 424.2482, found 424.2488.

Illudinine ethyl ester (35): $\mathrm{Pd} / \mathrm{C}(10 \%, 4.2 \mathrm{mg})$ was added to $34(10.1 \mathrm{mg}, 0.024$ mmol) in mesitylene $(190 \mu \mathrm{L})$ and the mixture was heated at $185^{\circ} \mathrm{C}$ for $4 \mathrm{hrs}$. The reaction was cooled, diluted with EtOAc and a few drops of TEA, filtered over a silica plug eluting with EtOAc then $\mathrm{MeOH}$, and concentrated to dryness. The residue was purified by silica gel chromatography, eluting with hexanes/EtOAc (1:1) to give $4.1 \mathrm{mg}$

\footnotetext{
1 Not all quaternary carbons observed.
} 
(58\%) of 35 as a solid. ${ }^{1} \mathrm{H}$ NMR $\left(300 \mathrm{MHz}, \mathrm{CDCl}_{3}\right) \delta 9.56(\mathrm{br} \mathrm{s}, 1 \mathrm{H}), 8.54(\mathrm{br} \mathrm{s}, 1 \mathrm{H})$, $8.31(\mathrm{~d}, J=4.7 \mathrm{~Hz}), 4.49(\mathrm{q}, J=7.2 \mathrm{~Hz}, 2 \mathrm{H}), 4.09(\mathrm{~s}, 3 \mathrm{H}), 3.10(\mathrm{~s}, 2 \mathrm{H}), 3.01(\mathrm{~s}, 2 \mathrm{H})$, $1.47(\mathrm{t}, J=7.2 \mathrm{~Hz}, 3 \mathrm{H}), 1.19(\mathrm{~s}, 6 \mathrm{H}) ;{ }^{13} \mathrm{C} \mathrm{NMR}\left(75 \mathrm{MHz}, \mathrm{CDCl}_{3}\right)^{1} \delta$ 167.2, 155.4 , 154.2, 146.9, 143.0, 135.6, 131.0, 119.1, 61.3, 61.0, 49.3, 44.9, 40.3, 28.5, 14.6. HRMS calcd for $[\mathrm{M}+\mathrm{H}]^{+} \mathrm{C}_{18} \mathrm{H}_{22} \mathrm{NO}_{3} 300.1594$, found 300.1603 .

Illudinine (36): To 35 (4.1 mg, $0.014 \mathrm{mmol})$ dissolved in $95 \% \mathrm{EtOH}(400 \mu \mathrm{L})$ was added $40 \%$ aqueous $\mathrm{KOH}$ (20 drops), and the reaction was stirred $20 \mathrm{hrs}$. Aqueous $\mathrm{HCl}(10 \%)$ was added to $\mathrm{pH} 3$, the solution poured into $\mathrm{pH} 7$ buffer and extracted with $\mathrm{Et}_{2} \mathrm{O}$. The organic layer was dried $\left(\mathrm{Na}_{2} \mathrm{SO}_{4}\right)$, filtered and concentrated to give $3.9 \mathrm{mg}(100 \%)$ of pure illudinine. ${ }^{1} \mathrm{H}$ NMR $(300 \mathrm{MHz}, \mathrm{MeOH}-\mathrm{d} 4) \delta 9.74(\mathrm{~s}, 1 \mathrm{H}), 9.02(\mathrm{~d}, J=6.9 \mathrm{~Hz}, 1 \mathrm{H})$, $8.53(\mathrm{~d}, J=6.9 \mathrm{~Hz}, 1 \mathrm{H}), 4.30(\mathrm{~s}, 3 \mathrm{H}), 3.28(\mathrm{~s}, 2 \mathrm{H}), 3.25(\mathrm{~s}, 2 \mathrm{H}), 1.22(\mathrm{~s}, 6 \mathrm{H}) ;{ }^{13} \mathrm{C}$ NMR $(75 \mathrm{MHz}, \mathrm{MeOH}-\mathrm{d} 4) \delta 169.4,164.6,158.1,144.2,140.3,134.6,133.7,124.8$, 124.0, 121.6, 62.7, 51.7, 47.1, 42.1, 29.1. HRMS calcd for $[\mathrm{M}+\mathrm{H}]^{+} \mathrm{C}_{16} \mathrm{H}_{18} \mathrm{NO}_{3}$ 272.1281, found 272.1283 .

Microwave Pressure/Temperature Curves for Representative Cyclotrimerizations. The microwave synthesizer employed (CEM Discover) allows for the simultaneous measurement of microwave power, temperature, and pressure over the course of the reaction.

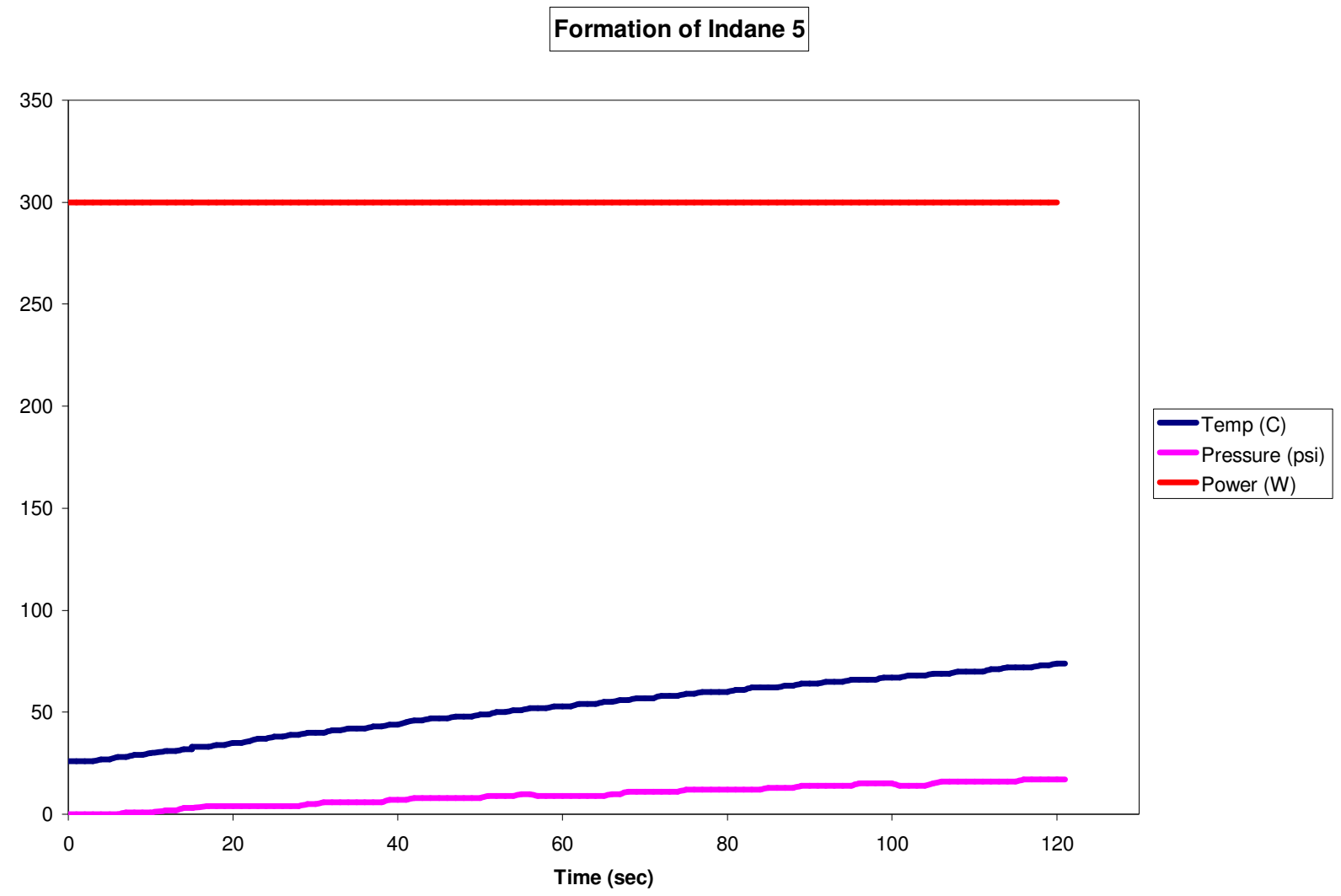


Formation of Isoindoline 11

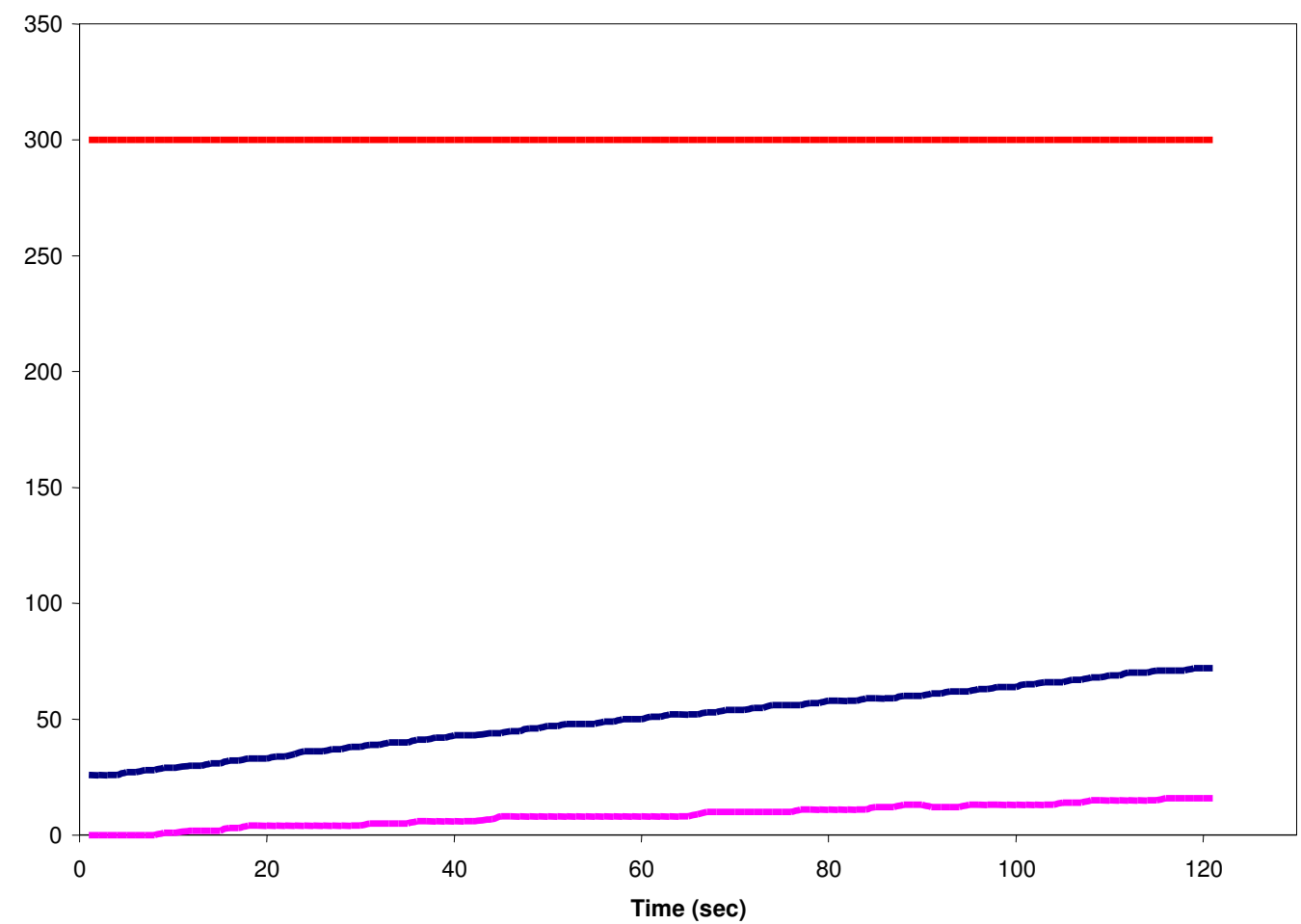

Temp (C)

- Pressure (psi)

- Power (W)

Formation of Indane 18

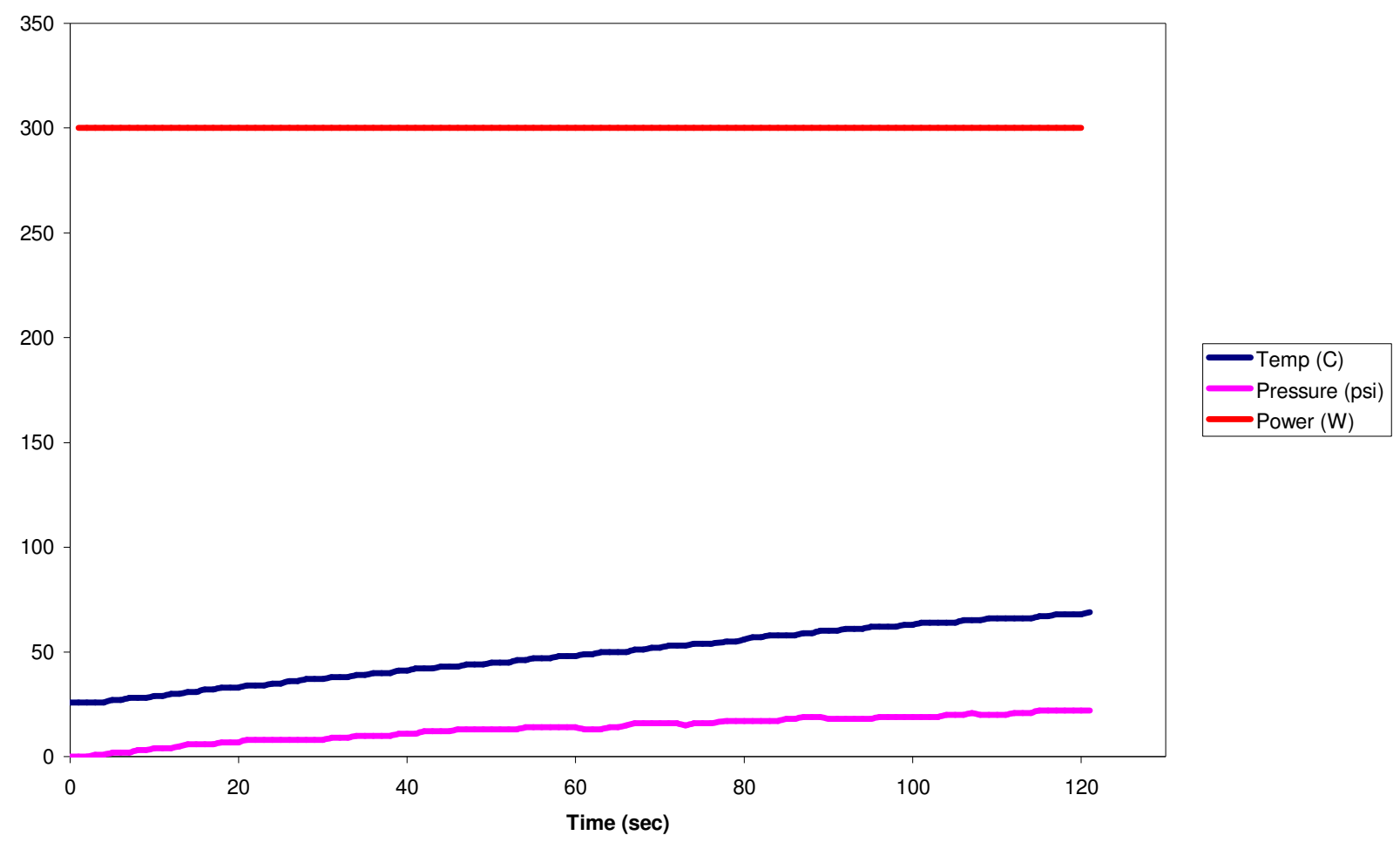


Formation of Tetralin 23

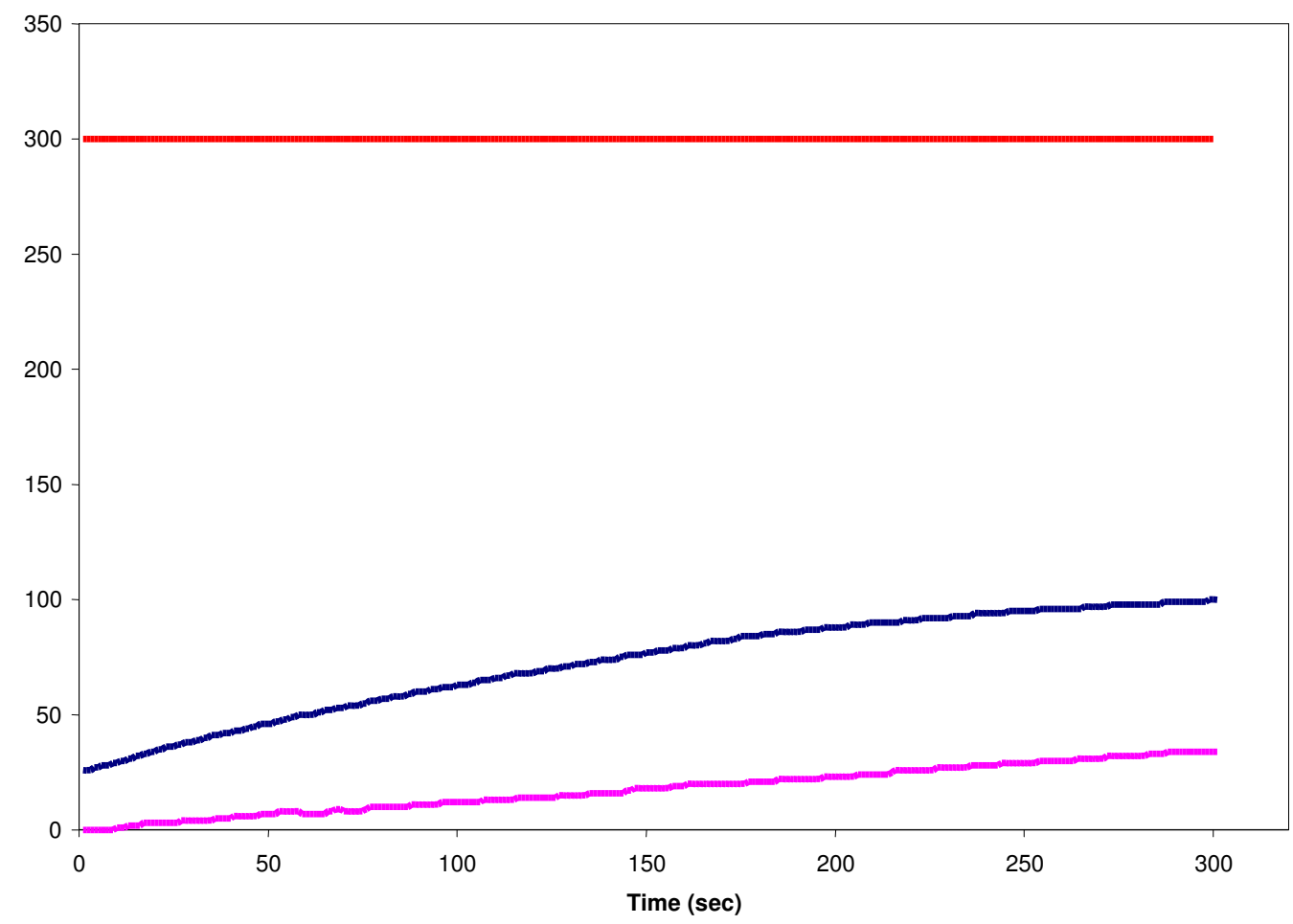

-Temp (C)

- Pressure (psi) - Power (W) 
${ }^{1} \mathrm{H}$ NMR Spectra for Compounds 9-15, 18-27, 29, and 31-36 (300 MHz)
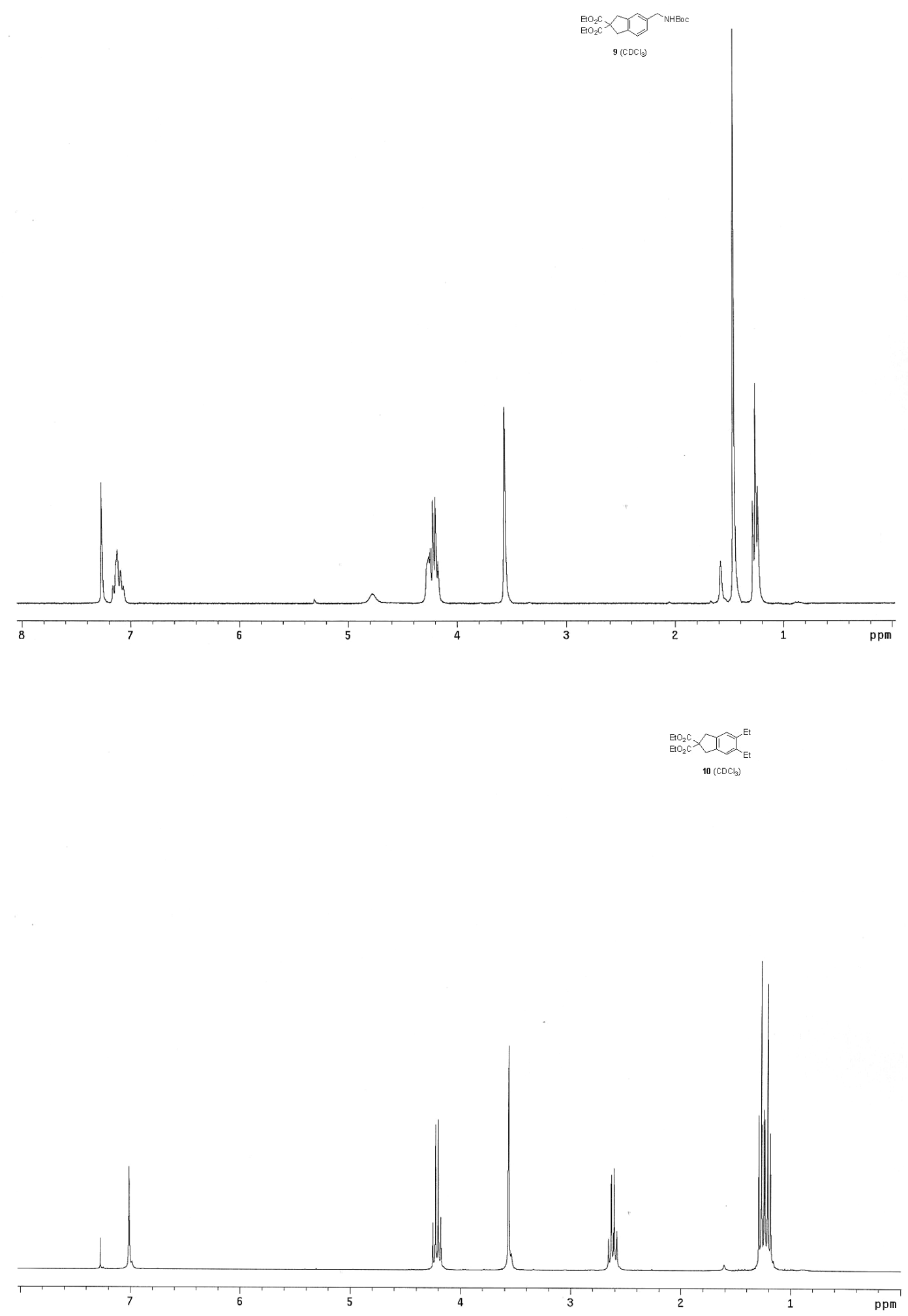


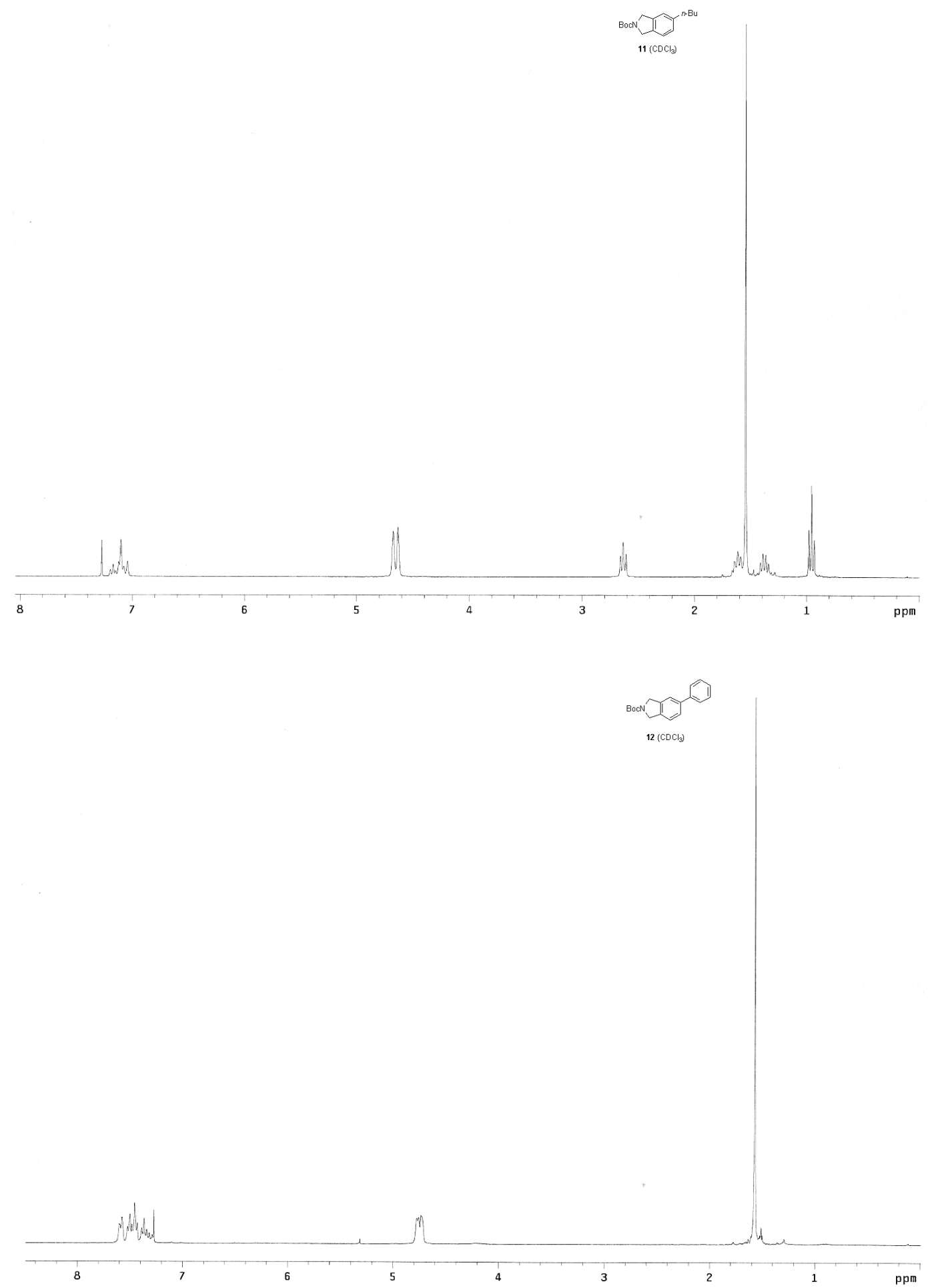




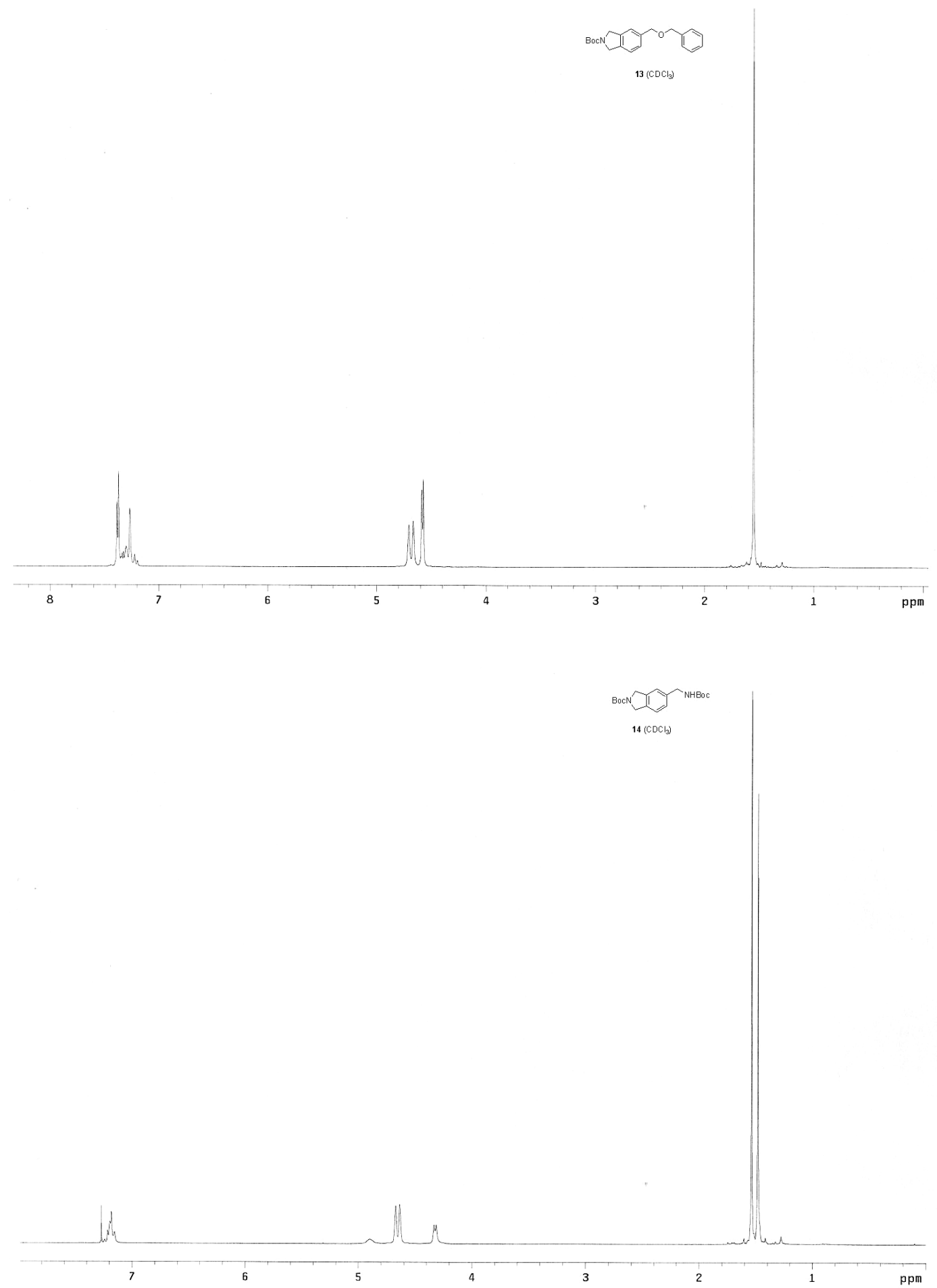



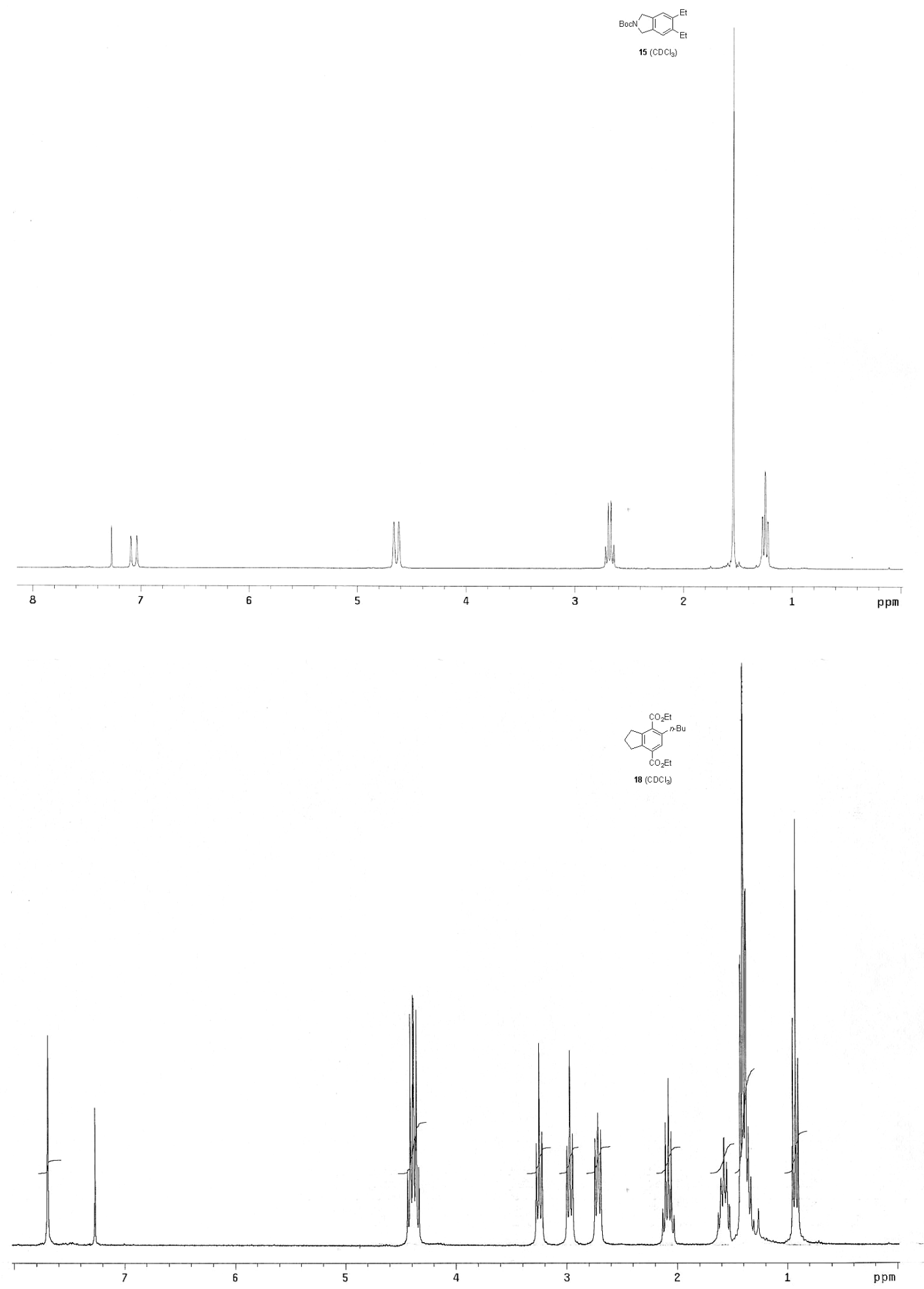

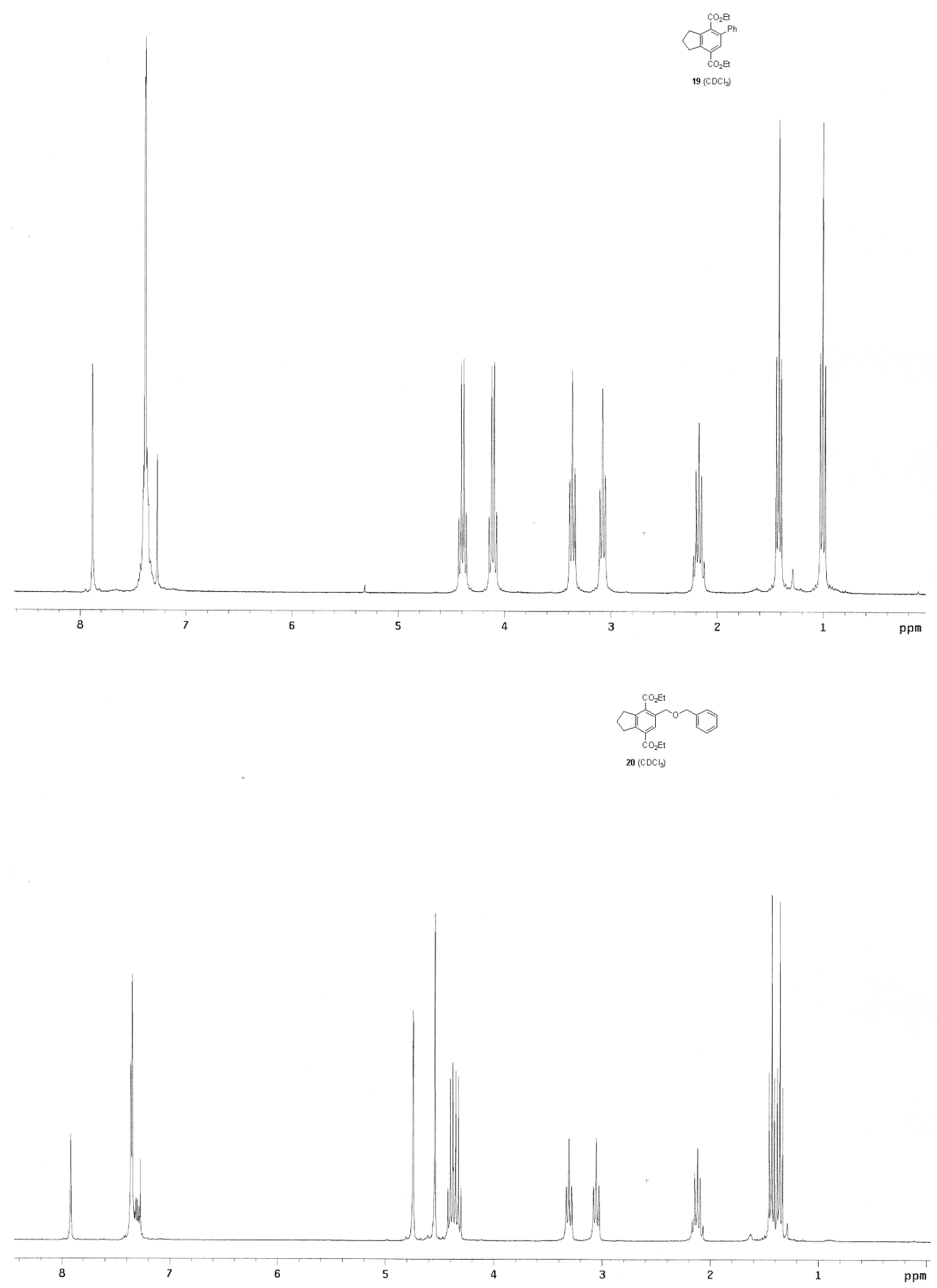

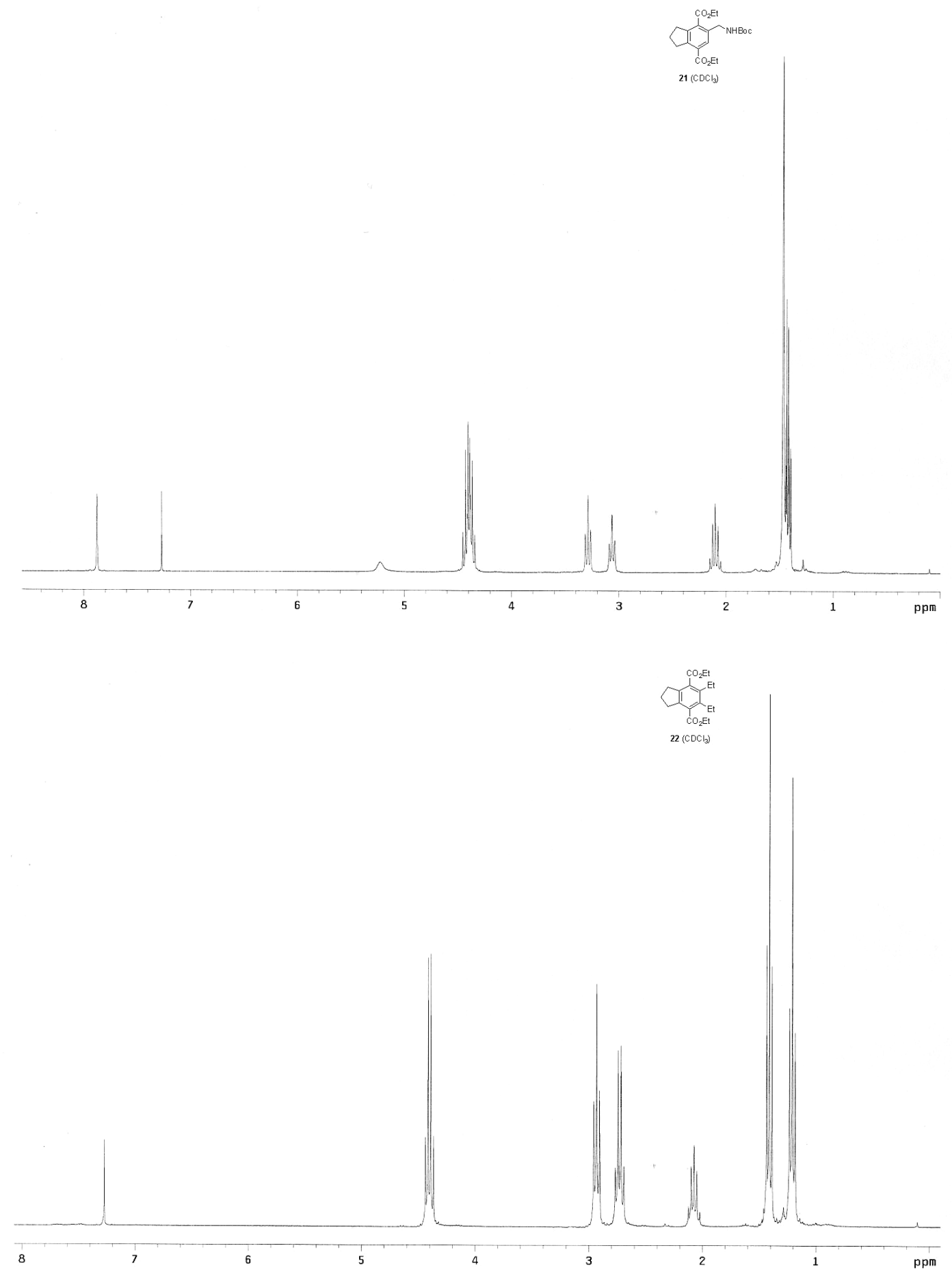


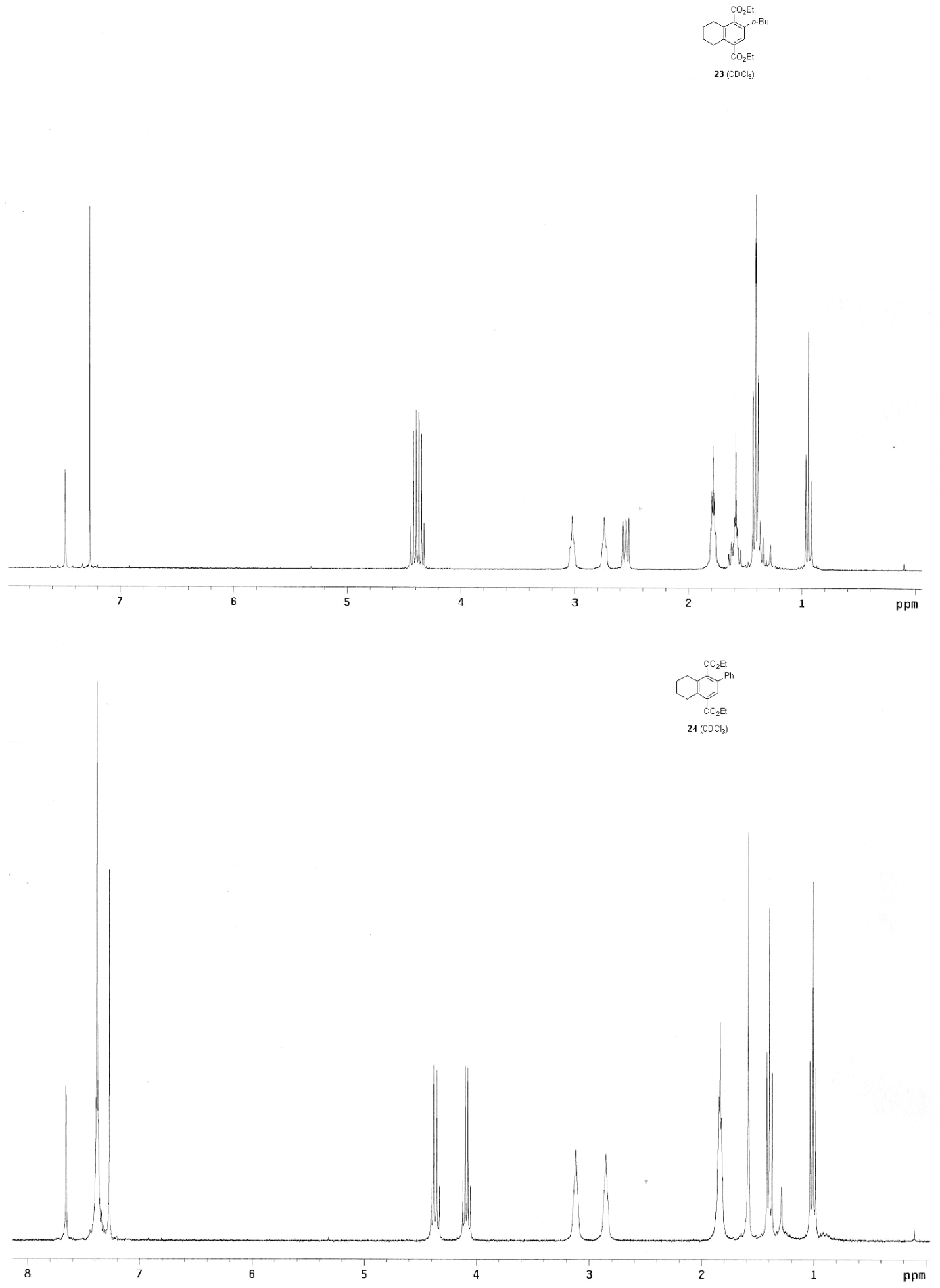



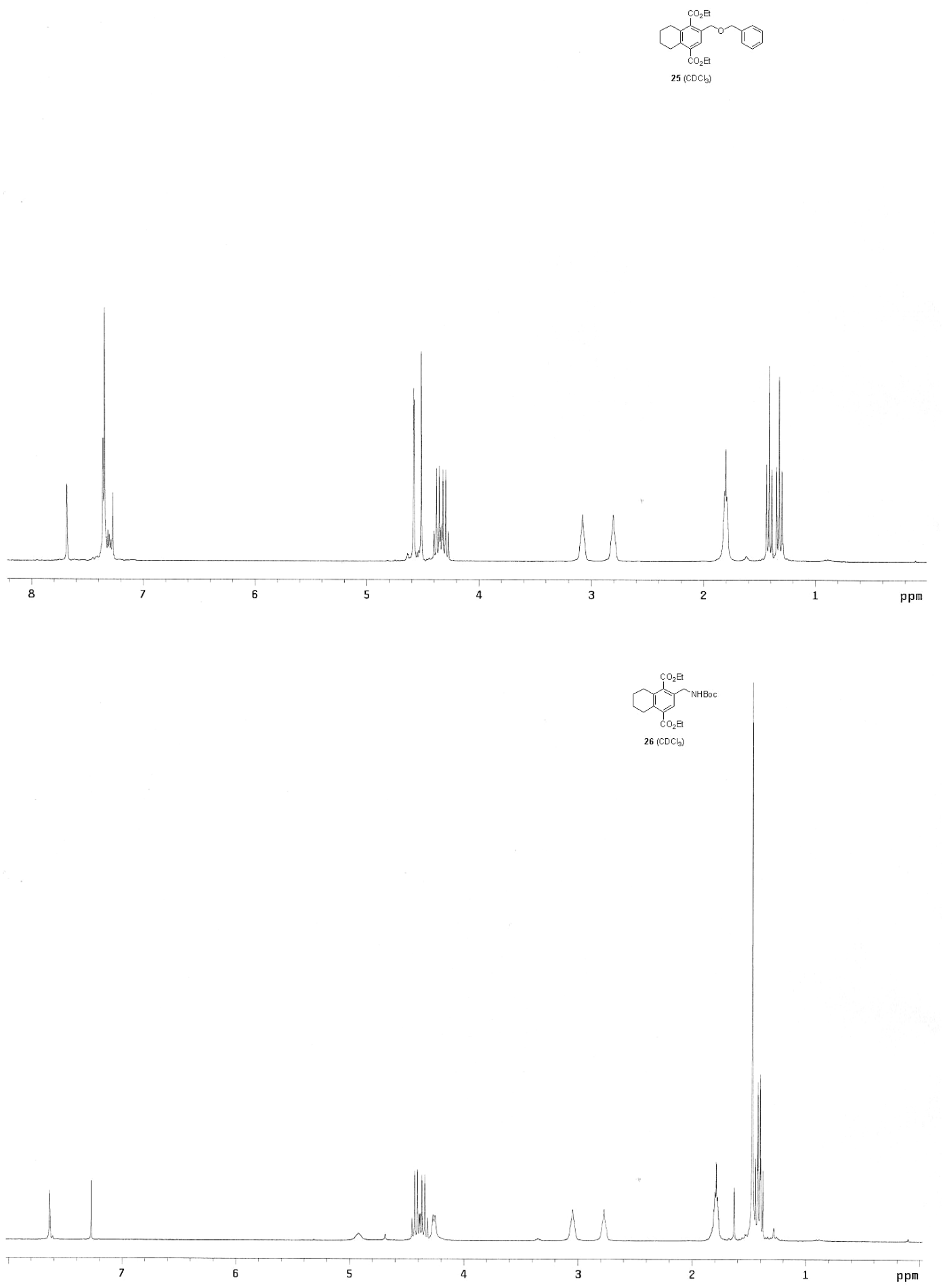


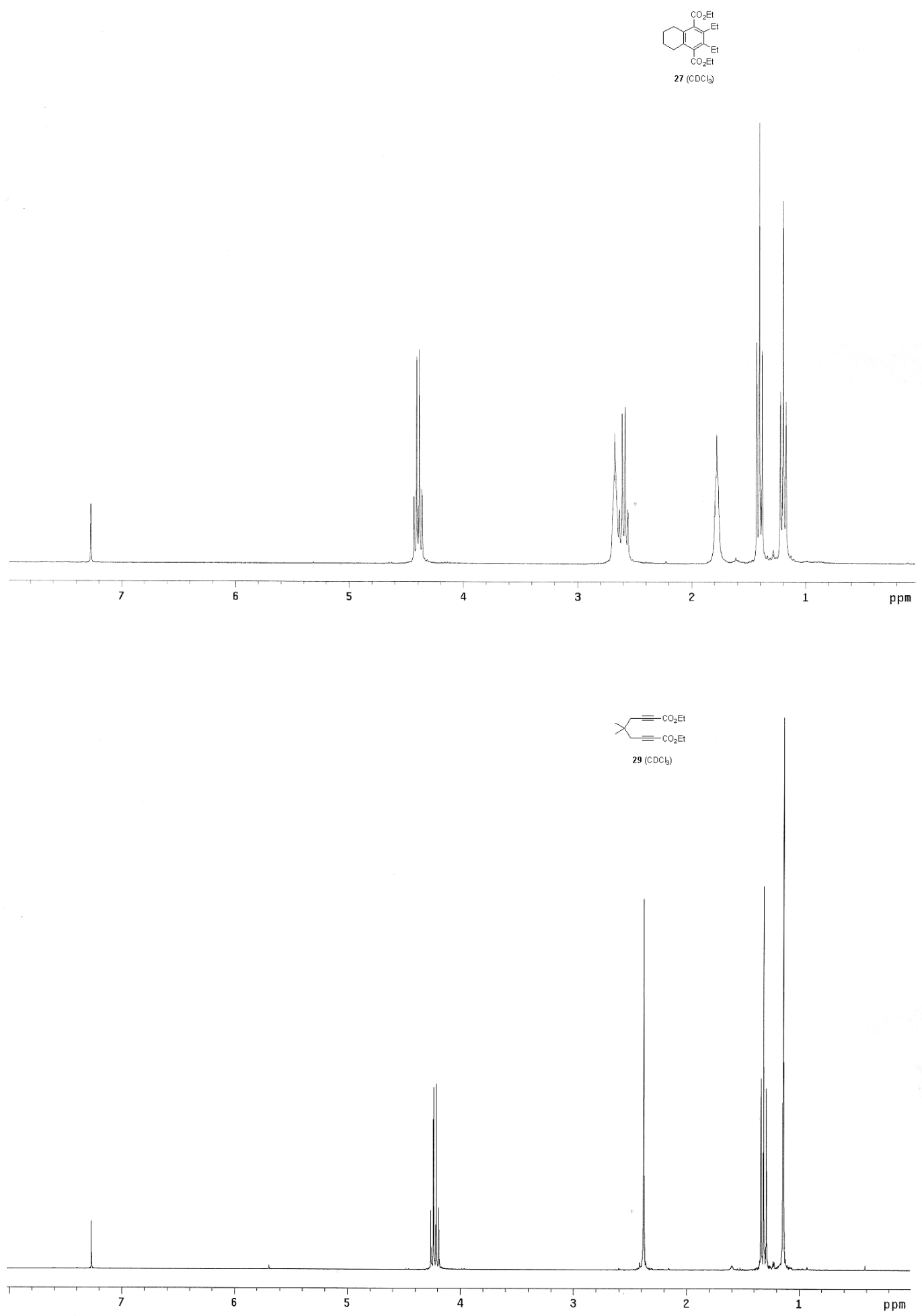




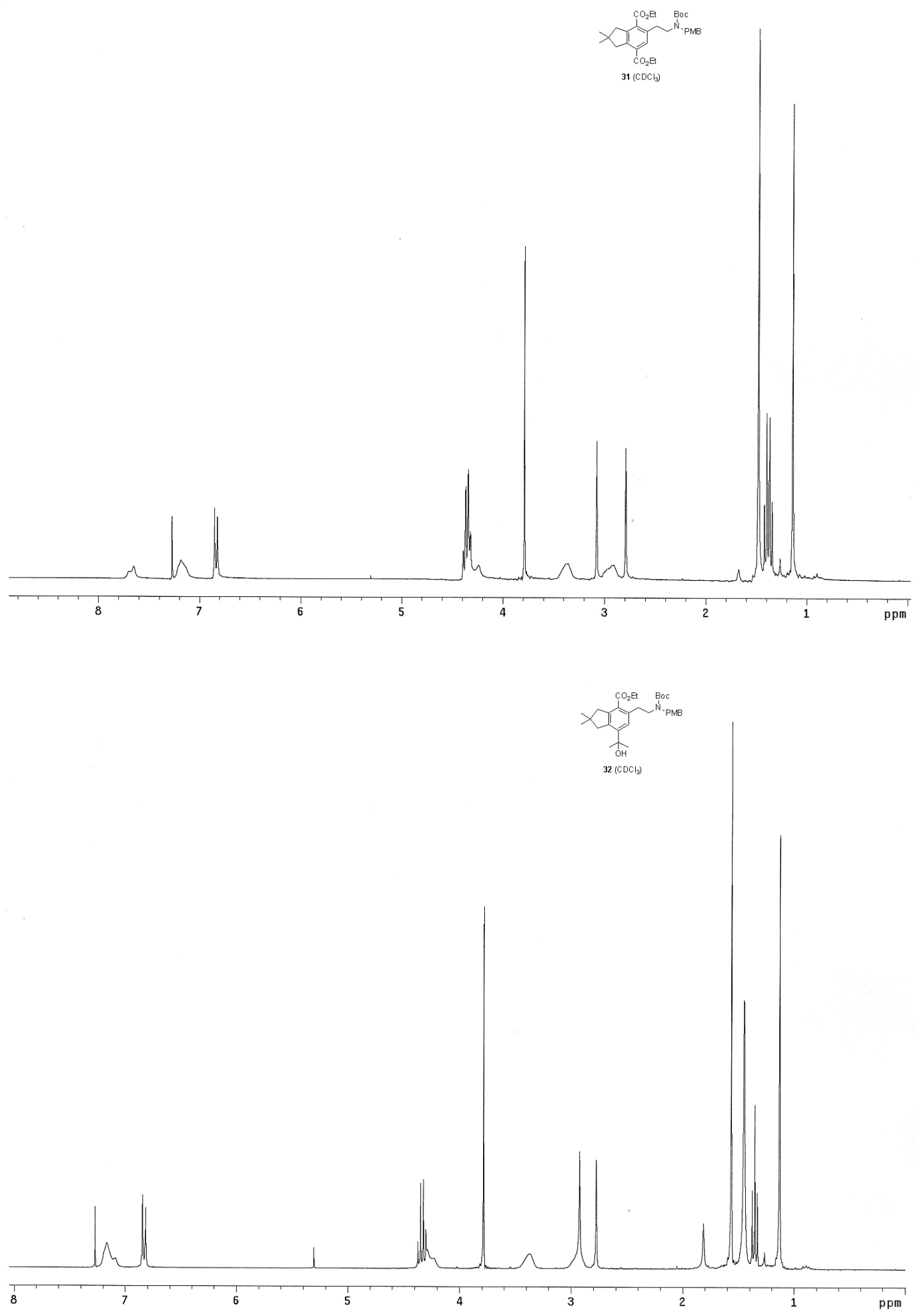



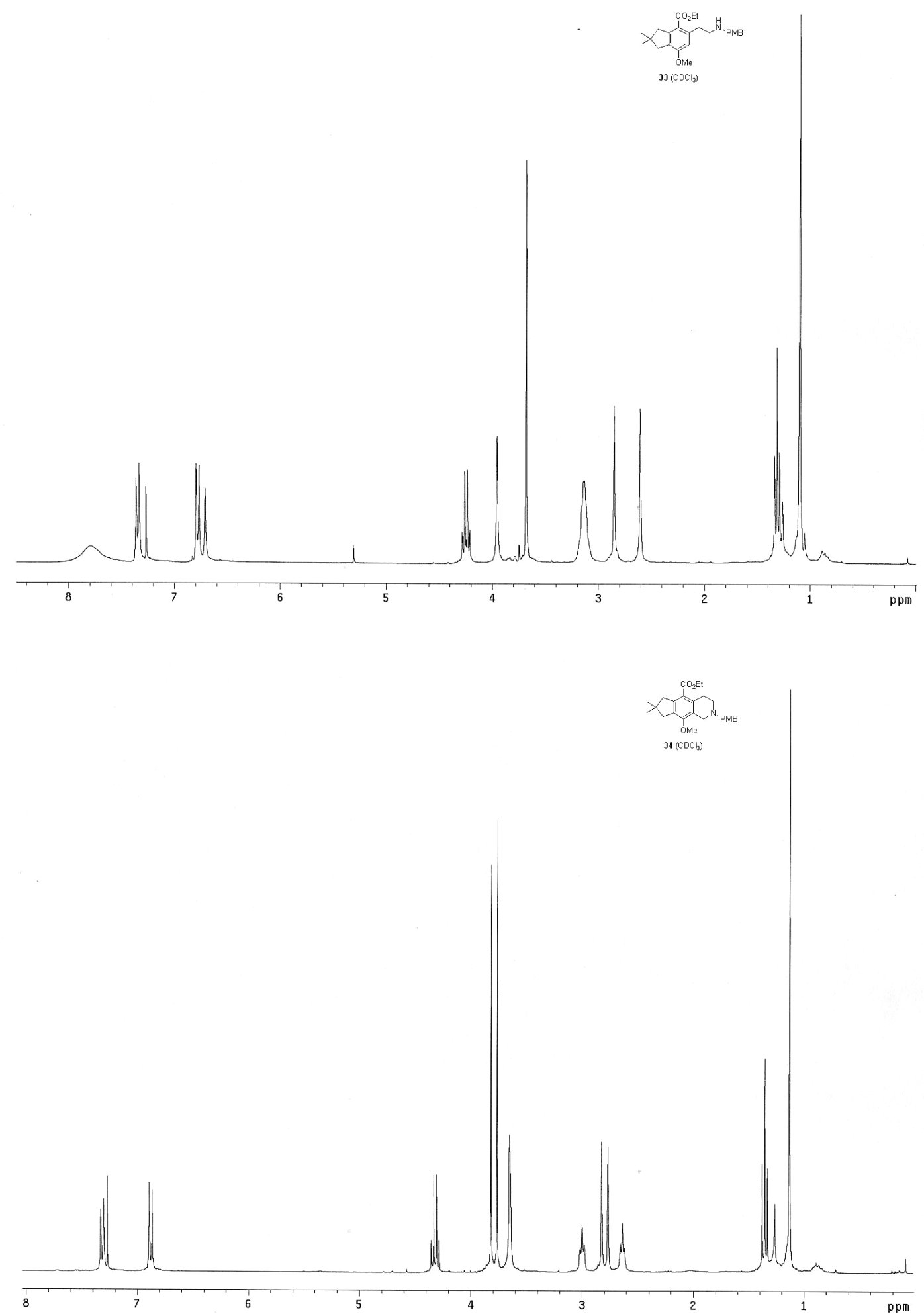

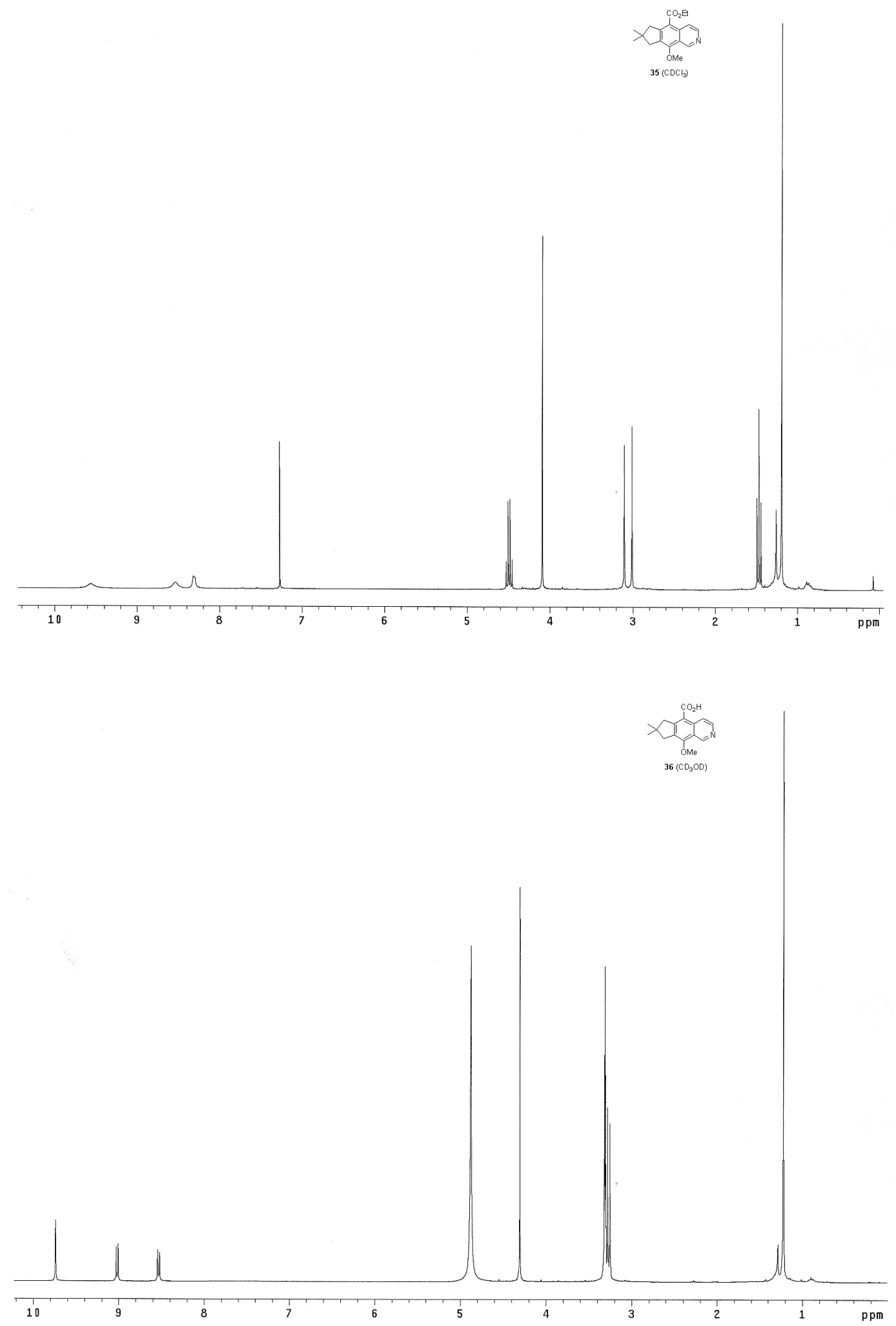


\section{${ }^{13} \mathrm{C}$ NMR Spectrum of 36}

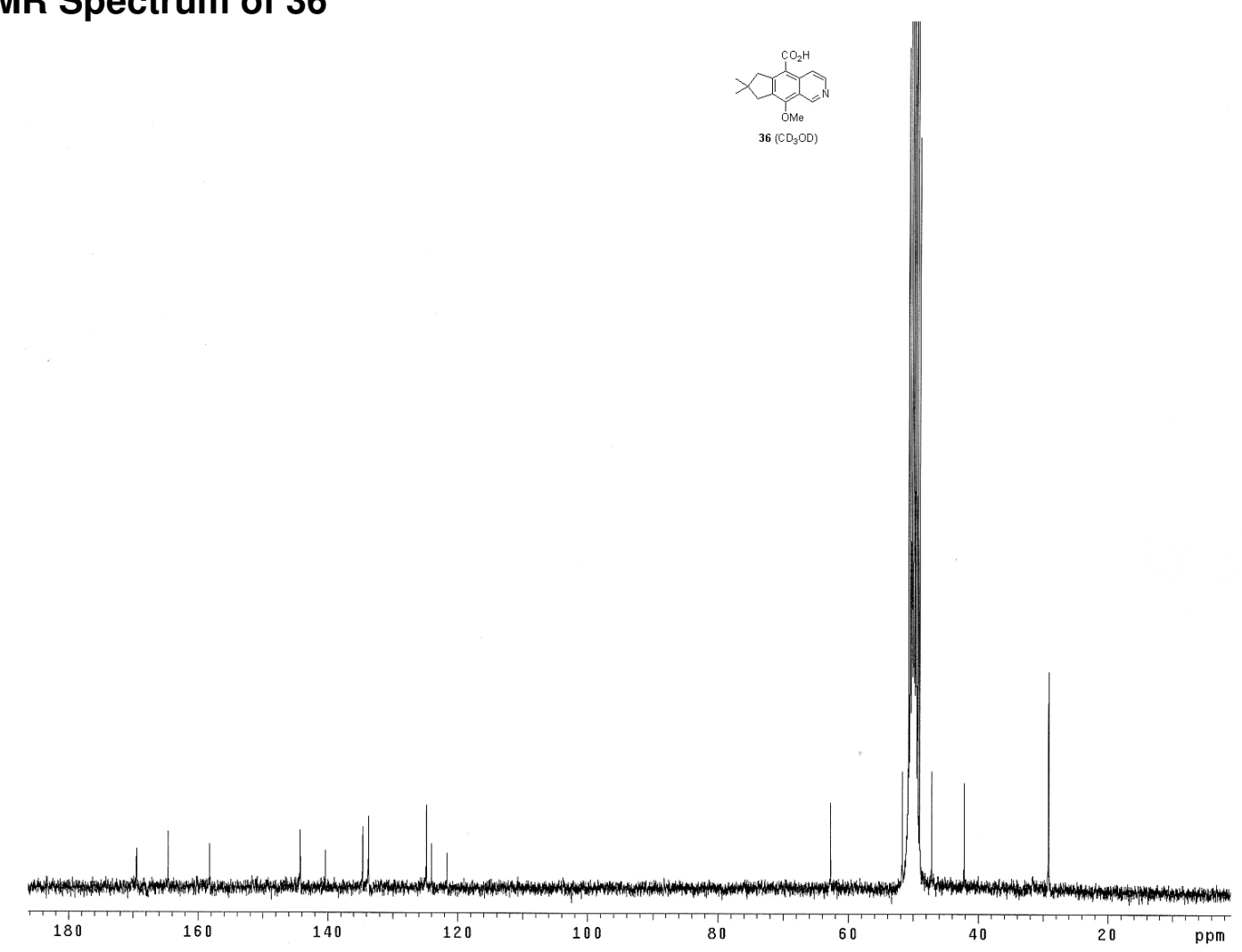

